\title{
OPEN ITRAQ-based proteome profiling revealed the role of Phytochrome A in regulating primary metabolism in tomato seedling
}

\author{
Sherinmol Thomas ${ }^{1}$, Rakesh Kumar ${ }^{2,3}{ }^{3}$ Kapil Sharma ${ }^{2}$, Abhilash Barpanda ${ }^{1}$, \\ Yellamaraju Sreelakshmi ${ }^{2}$, Rameshwar Sharma ${ }^{2}$ \& Sanjeeva Srivastava ${ }^{1 \bowtie}$
}

In plants, during growth and development, photoreceptors monitor fluctuations in their environment and adjust their metabolism as a strategy of surveillance. Phytochromes (Phys) play an essential role in plant growth and development, from germination to fruit development. FR-light (FR) insensitive mutant ( $f r i)$ carries a recessive mutation in Phytochrome $A$ and is characterized by the failure to de-etiolate in continuous FR. Here we used iTRAQ-based quantitative proteomics along with metabolomics to unravel the role of Phytochrome $A$ in regulating central metabolism in tomato seedlings grown under FR. Our results indicate that Phytochrome $A$ has a predominant role in FR-mediated establishment of the mature seedling proteome. Further, we observed temporal regulation in the expression of several of the late response proteins associated with central metabolism. The proteomics investigations identified a decreased abundance of enzymes involved in photosynthesis and carbon fixation in the mutant. Profound accumulation of storage proteins in the mutant ascertained the possible conversion of sugars into storage material instead of being used or the retention of an earlier profile associated with the mature embryo. The enhanced accumulation of organic sugars in the seedlings indicates the absence of photomorphogenesis in the mutant.

Plant development is intimately bound to the external light environment. Light drives photosynthetic carbon fixation and activates a set of signal-transducing photoreceptors that regulate plant growth and development. Plants have evolved an extraordinary degree of developmental plasticity to optimize their growth and metabolism in response to the changing environmental conditions. To sense different features of light such as quality, quantity, direction, duration of photoperiod, and integration of these signals to initiate the appropriate physiological and developmental response; plants have evolved a diverse set of photoreceptors ${ }^{1,2}$. Phytochromes that sense red (R) and far-red light $(\mathrm{FR})^{3}$ are photoreceptors with which plants gather environmental information and play a critical role in growth and development. Phytochrome A (PhyA), a photolabile phytochrome, is a unique photoreceptor which mediates FR high irradiance response (FR-HIR) of etiolated seedlings ${ }^{4}$.

Understanding the roles of PHYs in primary metabolism, especially carbohydrate metabolism, is of great importance in crop improvement practices under controlled light environments such as glasshouses ${ }^{5}$. Several "omics" studies, particularly transcriptomics, revealed that PhyA-mediated photomorphogenic responses involve global changes in gene expression ${ }^{6}$. In response to far-red and white light, PhyA regulates several primary metabolites, including amino acids, organic acids, and major sugars in Arabidopsis ${ }^{7}$. Subsequently, it was reported that loss of phytochrome impacts core metabolism and over-accumulation of a large number of primary metabolites have been observed in leaves of the Arabidopsis phyBD and phy ABDE mutants ${ }^{8}$.

Since proteins are directly involved in various cellular functions, a comprehensive proteomic investigation is likely to provide an insight into the intracellular changes as a result of the loss of photoreceptors. A few studies have reported the proteomics alterations in tomato seedling during the early stage of development, but their research was mainly focused either on proteome profiling of skotomorphogenesis or the changes in proteome during the transition from dark to red light. Therefore, the present study was undertaken to unravel the specific role of PhyA in regulating central metabolism during FR treatment using a high-throughput iTRAQ (isobaric tags

${ }^{1}$ Proteomics Lab, Department of Biosciences and Bioengineering, IIT Bombay, Mumbai, Maharashtra 400076, India. ${ }^{2}$ Repository of Tomato Genomics Resources, Department of Plant Sciences, University of Hyderabad, Hyderabad 500046, India. ${ }^{3}$ Deptartment of Life Science, Central University of Karnataka, Kadaganchi, Kalaburagi, Karnataka 585367, India. ${ }^{\square}$ email: sanjeeva@iitb.ac.in 
for relative and absolute quantitation) based quantitative proteomics. Furthermore, GC-MS-based metabolite profiling was also performed to understand the underlying metabolite variation. In the present study, we also identified differentially expressed late response proteins in a longitudinal manner by taking a two-time point of data acquisition in every experiment. These proteins displayed a significantly altered expression and represented the foremost altered physiological pathways.

\section{Results and discussion}

To facilitate photomorphogenesis, plants have evolved an array of photoreceptors, which capture a wide range of light spectrum and alter a myriad of physiological processes upon reception of the light signal ${ }^{9,10}$. Phytochromes that sense red (R) and far-red light $(\mathrm{FR})^{3}$ are photoreceptors with which plants gather environmental information and play a critical role in growth and development. Following light exposure, signaling and transcription factor genes tend to be induced/repressed early, while genes in energy metabolism and photosynthesis were affected later. Metabolomics and gene expression studies of various species ${ }^{6-8,11}$ revealed the role of various photoreceptors in regulating primary metabolism in plants.

In the current study, we employed a proteomics-based analysis of tomato fri mutant grown under FR compared to Ailsa Craig (AC) seedlings as control, which has a functional Phytochrome A. Our results revealed key mechanistic insights for the understanding of functional mechanisms underlying in the process of FR lightmediated signal transduction. The majority of PhyA regulated genes displayed changes in their expression after several hours under FR, and these 'late response genes' represent genes involved in photosynthesis and chloroplast development. It is assumed that many downstream components are regulated after a longer duration of light treatment. The time points 48 and $96 \mathrm{~h}$ were taken into account to get a comprehensive insight into FR-mediated late response pathways.

In the present study, we first looked into the proteomic alteration as a result of FR irradiation in the wild-type AC seedlings. Subsequently, we checked the effect of loss of PHYA in FR-mediated signaling by studying the differential protein expression of fri mutant compared to AC. Additionally, we performed differential protein expression analysis of fri mutant and AC seedlings grown under dark to understand the specific role of phyA in the dark. To accomplish this, we performed integrated proteomics and metabolomics-based deep investigation. Mass spectrometry (MS) based quantitative proteomics has facilitated the identification of functional modules and pathways and prediction of biomarkers ${ }^{12,13}$. Quantitative results can be obtained using stable isotope labels or label-free methods ${ }^{14-16}$. Typically, isotope labels offer better reproducibility in quantitation than label-free methods as the latter require highly reproducible LC-MS/MS platforms ${ }^{16}$. The iTRAQ based data analysis strives to report reliable relative protein quantification; however, discrepancies in quantification might occur due to the low abundance of peptides, smaller sample size, complicated experimental procedures, and lack of suitable internal standards ${ }^{17-19}$. Notwithstanding several drawbacks, iTRAQ is one of the most flexible techniques that allow multiplexing of four, six, and eight separately labeled samples within one experiment, which ensures the reduction of costly LC-MS runtime en-22. $^{19}$.

Metabolite profiling has also been considered as a powerful tool to examine the regulatory mechanisms of metabolic pathways in plants ${ }^{23-25}$. Although LC-MS is the most widely used platform for the analysis of intermediate molecules, from the past few decades, GC-MS has also been used to identify and quantify metabolites such as Calvin cycle pathway intermediates ${ }^{26}$. In the current study, proteomic and metabolite profiling data have been integrated to investigate the regulation of various biochemical pathways in tomato, which revealed a crucial relationship between signal transduction and metabolic pathways.

Protein identification and quantification. In this study, we used Ailsa Craig (AC) and fri (far-red insensitive) mutant seedlings of tomato grown under FR light and dark. To understand the temporal variation in the expression, two-time points (48 and $96 \mathrm{~h}$ ) of data acquisition were employed in every experiment (Fig. 1A). Three independent biological replicates of seedling samples were used for the iTRAQ experiment, and the detailed iTRAQ labeling strategy is shown in Supplementary Fig. S1. The iTRAQ reaction sets 1, 3, and 5 represent FR light-treated mutant and AC, while sets 2, 4, and 6 represent dark-grown seedlings. A total of 1519 proteins were identified in three biological replicates (Supplementary Table S1), and 289 proteins were found to be present in all the 3 replicates (Fig. 1C). 438 and 394 common proteins were found in FR and dark-grown samples, respectively (Fig. 1C). Raw abundance, normalized abundance, grouped abundance and abundance ratio of these proteins at various treatment conditions, is shown in Supplementary Table S1.

Gene ontology (GO) database, Panther classification system (http://www.pantherdb.org/) ${ }^{27}$ was used to categorize all of the identified proteins, and gene ontology (GO) analysis allowed us to understand the different functions and process in which the proteins are involved (Fig. 2C, Supplementary Fig. S2A and S2B). The molecular function (Supplementary Fig. S2A), cellular component (Supplementary Fig. S2B), and biological process Fig. $2 \mathrm{C}$ of the proteins are presented. According to the biological process analysis (Fig. 2C (a)), most of the proteins were related to cellular process $(37 \%)$ and metabolic processes (30\%). Most of the proteins were found in the Cell part (26\%) or cell region (26\%) as shown in Supplementary Fig. S2B (a) by cellular component analysis. Concerning Molecular function (Supplementary Fig. S2A (a)), the identified proteins were involved in catalytic activity (48\%) and binding (34\%). The identified proteins were filtered to verify whether the changes in protein abundance are significant based on the cutoff values with a fold change $<0.66$ or $>1.5$, and $p$ value $<0.05$. We performed our analysis in three categories: (1) differential protein expression analysis of AC seedlings irradiated with FR in comparison to dark control (AC/FR versus AC/D); (2) differential expression analysis of PhyA mutant (fri) seedlings irradiated with FR in comparison to AC seedlings (fri/FR versus AC/FR) to examine the role of light and the specific role of PhyA, respectively in regulating primary metabolism; and (3) differential 
A
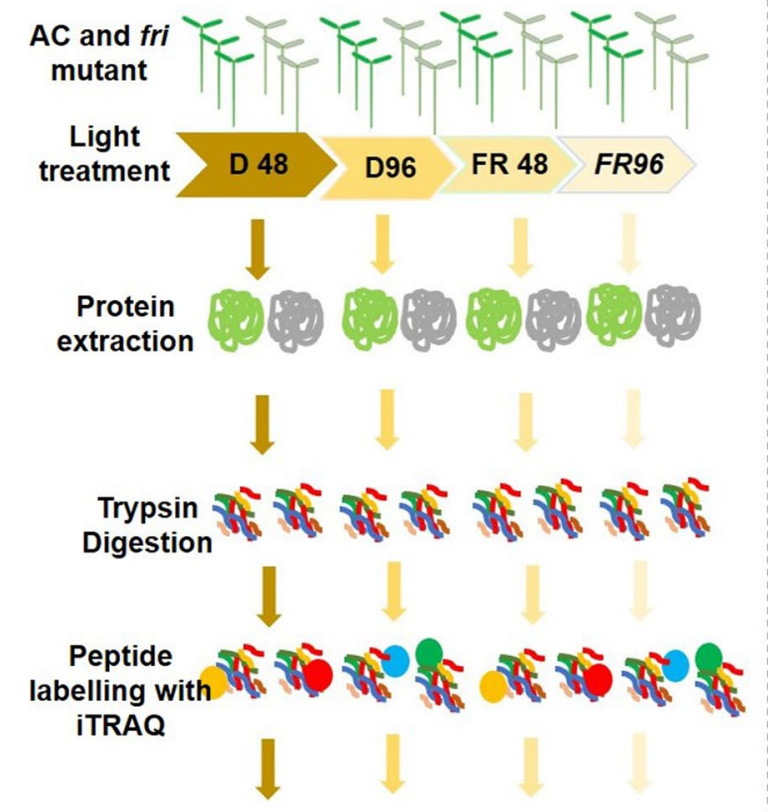

LC-MS/MS using

Orbitrap Q

Exactive

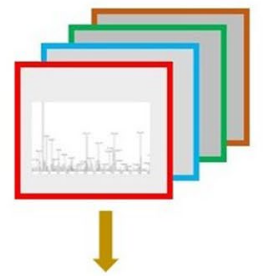

Data Analysis

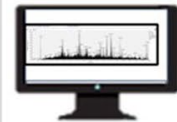

Database search

Protein Identification and quantification using PD software
B
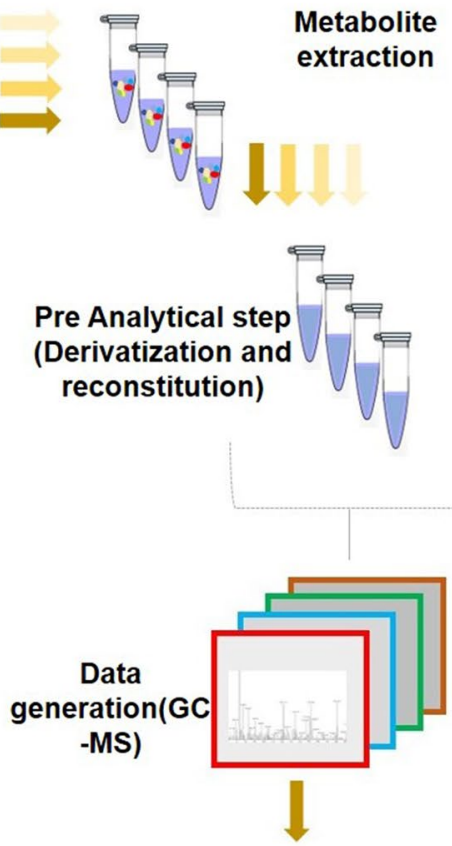

Data processing(data cleaning, feature extraction, alignment and data base search)
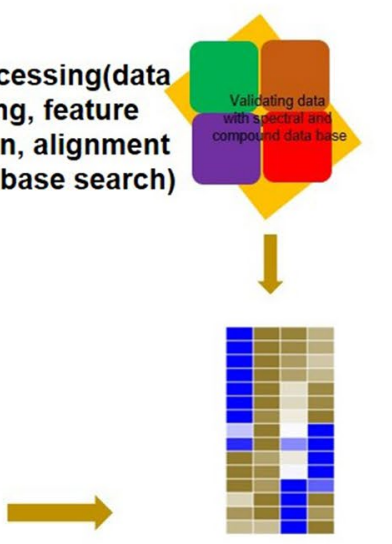

Statistical analysis and

biological interpretation

\section{SET 1 SET 3 SET 2 SET 4}

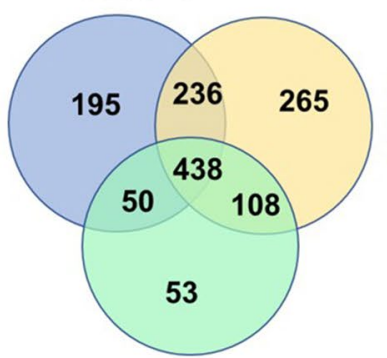

SET 5

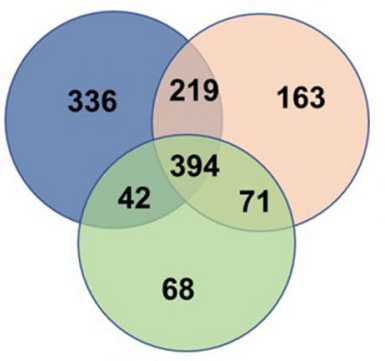

SET 6
FR Dark

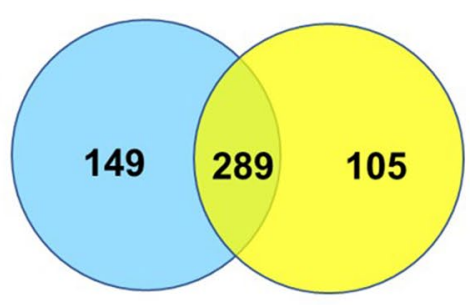

Figure 1. Quantitative proteomics and metabolite profiling of tomato seedlings to understand the role of PhyA in FR light-mediated photomorphogenesis. (A) Schematic illustration of the overall experimental strategy used in the discovery-phase global quantitative proteomics and metabolomics. (B) Venn diagram showing the unique and overlapping proteins identified in specific light treatment at two different time points. 

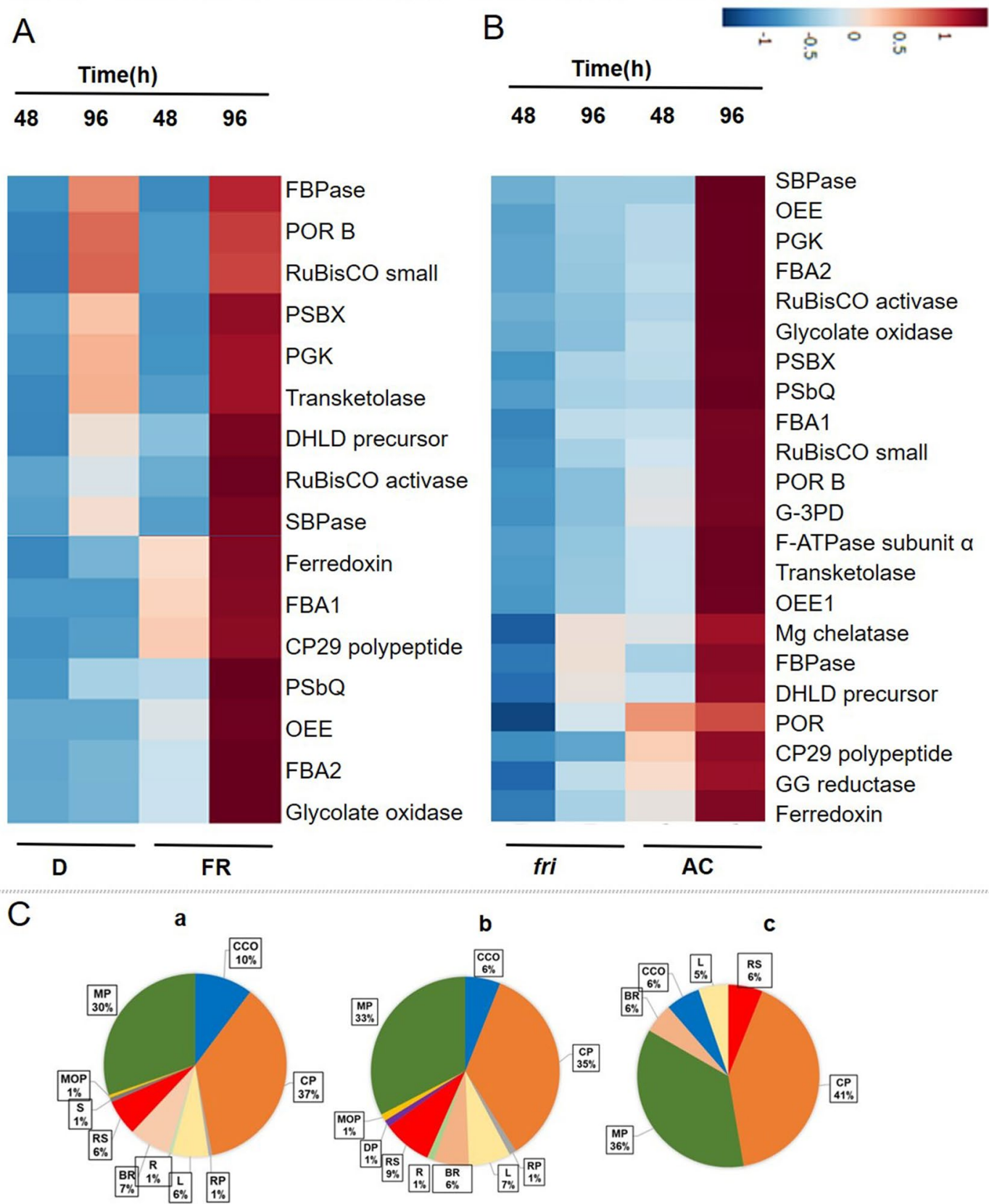

Figure 2. Quantitative proteomics to understand the role of PhyA in the light-mediated establishment of the photosynthetic machinery. (A) Heat map illustrating the fold ratio of differentially altered proteins in the central carbon metabolic pathways in response to FR irradiation in AC seedling in comparison to dark-grown AC control. (B) Heat map demonstrating the fold ratio of differentially altered proteins in the fri mutant in comparison to AC seedlings under FR irradiation. OEE1-33 kDa precursor protein of oxygen-evolving complex; OEE-The oxygen-evolving enhancer protein; DHLD precursor-dihydrolipoamide dehydrogenase precursor; RuBisco-ribulose-1,5bisphosphate carboxylase or oxygenase; PGK-phosphoglycerate kinase; G3PD: glyceraldehyde-3-phosphate dehydrogenase; SBPase- Sedoheptulose 1,7-bisphosphatase; Mgprot IX-Mg-protoporphyrin IX chelatase; GG reductase-Geranylgeranyl reductase; Por-light dependent NADH:protochlorophyllide oxidoreductase 1; PorB-light dependent NADH:protochlorophyllide oxidoreductase 3 s2; FBA1-Fructose-bisphosphate aldolase 1, FBA2-Fructose-bisphosphate aldolase; F ATPase subunit $\alpha$-ATP synthase subunit alpha; PsbX-psbX photosystem II $23 \mathrm{kDa}$ protein; PsbQ-photosystem II oxygen-evolving complex protein; (C) The GO terms identified for biological process (a) in all the identified proteins (b) significant proteins identified in the comparison of Dark vs FR in Ailsa craig (c) significant proteins identified in the comparison of Ailsa craig vs fri mutant grown under FR light. CCO (cellular component organization or biogenesis), CP (cellular process), RP (reproductive process), L (localization), BR (biological regulation), $\mathrm{R}$ (reproduction), RS (response to stimulus), DP (developmental process), MOP (multicellular organismal process), MP (metabolic process) and S (Signaling). 
expression analysis of PhyA mutant (fri) seedlings in comparison to AC seedlings under dark (fri/D vs AC/D) to examine the specific roles of Phy A in dark.

The statistically significant proteins (ANOVA passed $p<0.05$ ) from both the groups AC/FR versus AC/D and $\mathrm{fri} / \mathrm{FR}$ versus AC/FR were further subjected to PLS-DA (partial least squares discriminant analysis) using an online tool MetaboAnalyst $4.0^{28}$. Based on the differences among the protein fold ratio values on a 2D-score plot, the four groups that are segregated in AC/FR versus AC/D group analysis were ACD48, ACD96, ACFR48, and ACFR96 (Supplementary Fig. S3B). Similarly, MUTFR48, MUTFR 96, ACFR48, and ACFR96 were the 4 groups segregated in the analysis of fri/FR versus AC/FR (Supplementary Fig. S4B). Further, a heat map was generated demonstrating the differential expression (fold ratio pattern) of a few of these proteins involved in photosynthesis and carbon metabolism processes and is presented in Fig. 2A,B.

The differentially expressed proteins obtained in the iTRAQ study were integrated and highlighted in all possible KEGG (Kyoto Encyclopedia of Genes and Genomes) metabolic pathways using the KEGG Mapper tool ${ }^{29}$. Mapping of differentially expressed proteins indicated major perturbations in pathways associated with central metabolism. The coverage of the differentially expressed proteins was assessed using Plant-mPLoc (http://www. csbio.sjtu.edu.cn/bioinf/plant-multi/ $)^{30}$. Most of the proteins belonged to plastids, vacuoles, and mitochondria (Table 1).

Temporal regulation of protein expression during the early development of $\mathrm{AC}$ seedlings. The proteome profile of FR-grown AC seedlings compared to dark-grown seedlings (AC/FR vs AC/D) revealed a total of 85 statistically significant proteins (Supplementary Fig. S3A) with high FDR confidence. Further, the selection was performed based on the fold ratio values ( $\geq 1.5$ fold up-regulation or $\leq 0.66$ fold down-regulation), and the resulting proteins were considered for the subsequent pathway analysis. Comprehensive iTRAQ data analysis revealed a subset of 21 proteins present in both the time-points, while 13 and 21 different proteins were expressed exclusively in 48 and 96 h of FR-treatment, respectively. These FR-regulated proteins displaying differential expression patterns (Fig. 2A and Table 2) may provide vital clues to understand the proteome perturbations in response to light. The functional annotations revealed that several proteins involved in photosynthesis, carbon assimilation, and nitrogen metabolism (Table 2) exhibited a steep increase in accumulation, particularly with an increase in FR duration from 48 to $96 \mathrm{~h}$. Interestingly, another set of proteins that are also involved in the establishment of photosynthetic machinery and carbon metabolism, showed an abundance independent of FR-treatment. However, the second category of proteins exhibited a temporal alteration in their accumulation profile in both FR-treated samples and dark controls. Our data suggest the presence of two distinct groups of proteins with either light-dependent or independent expression patterns (Fig. 2A). Most of the light-independent proteins showed a temporal variation with a significant change in their accumulation during $96 \mathrm{~h}$ of treatment (Fig. 2A and Table 2).

Light-dependent protein proteins such as Cp29, Ferredoxin, PSII oxygen-evolving complex protein 3(PSbQ), Oxygen-evolving enhancer protein 1(OEE), and Fructose-bisphosphate aldolase (FBA 1 and 2), are some of the prominent proteins associated with photosynthesis and carbon assimilation and exhibited a light-dependent expression. Consistent with the acquisition of photoautotrophy during de-etiolation, an increase in their abundance was perceptible at $48 \mathrm{~h}$ followed by a steep increase in abundance at $96 \mathrm{~h}$. Glycolate oxidase, one of the key proteins involved in photorespiration as well as mobilization of the stored reserve, too showed increased abundance with longer FR-irradiation (Fig. 2A).

Light independent protein Interestingly, PsbX (psbX photosystem II $23 \mathrm{kDa}$ protein), Rubisco activase, RUBISCO small subunit, etc., known for their important involvement in de-etiolation, exhibited a light-independent accumulation. Consistent with the need to sustain the energy need of the growing seedlings, the proteins associated with energy metabolism viz. phosphoglycerate kinase (PGK), transketolase, dihydrolipoamide dehydrogenase precursor (DHLD precursor), sedoheptulose-1,7-bisphosphatase (SBPase), fructose-1,6-bisphosphatase (FBPase), showed increased accumulation at $96 \mathrm{~h}$ than at $48 \mathrm{~h}$ (Fig. 2A). Interestingly, our study showed a light-independent, temporal increase in the abundance of POR B (Solyc10g006900.3.1), a prominent protein involved in chlorophyll synthesis (Fig. 2A and Table 2).

PhyA is unique within the phytochrome family, as it is solely responsible for seedling responsiveness to continuous far-red light $(\mathrm{FR})^{31,32}$. The de-etiolation process that occurs exclusively under $\mathrm{FR}^{31}$ provides an ideal opportunity to define the relationship between PhyA and its target gene ensemble. In Arabidopsis, gene expression profiling studies revealed that under FR irradiation, PhyA-regulated gene expression can be classified into 'early-response' genes and that accounts for $8 \%$ of total PhyA regulated expression ${ }^{6}$ and the late response genes whose expression manifest after several hours under FR.

Our data provides clues regarding the change in metabolism or regulation of protein levels during the transition from heterotrophic to autotrophic development. During heterotrophic-to-autotrophic transition, chloroplast development and differentiation are modulated by external light parameters and homeostasis of several plant hormones. These processes also include the regulation of gene expression, metabolites levels such as sugars, and reactive oxygen species ${ }^{33}$. Our results showed that the majority of proteins begin to accumulate after $48 \mathrm{~h}$ and reach their maximum response within $96 \mathrm{~h}$, which indicates that the major part of the cellular functions underlying the de-etiolation process is established between 48 to $96 \mathrm{~h}$ of the FR treatment. This pattern is most striking for the most abundant classes of late response proteins, especially proteins that are associated with photosynthesis/chloroplast and cellular metabolism.

Light-mediated photomorphogenesis is often coupled with modulation of gene expression leading to various morphological changes. Plants possess complex networks for the maintenance of metabolic balance, particularly primary metabolism, and are accompanied by changes in mRNA levels, protein accumulation, enzyme activities, and metabolite levels. In a dark-grown seedling, the photomorphogenic developmental pathway is repressed and 


\begin{tabular}{|c|c|c|c|}
\hline Sl.no & Accession no & Entry name & Subcellular compartment \\
\hline 1 & Solyclog006900.3.1 & Light dependent NADH:protochlorophyllide oxidoreductase $3 \mathrm{~s} 2$ & Chloroplast \\
\hline 2 & Solyc07g044860.3.1 & psbXphotosystem II $23 \mathrm{kDa}$ protein & Chloroplast \\
\hline 3 & Solyc07g032640.2.1 & Oxygen-evolving enhancer protein 1 & Chloroplast \\
\hline 4 & Solyc02g065400.3.1 & $33 \mathrm{kDa}$ precursor protein of oxygen-evolving complex & Chloroplast \\
\hline 5 & Solyc02g079950.3.1 & Photosystem II oxygen-evolving complex protein 3 & Chloroplast \\
\hline 6 & Solyc06g060340.3.1 & Photosystem II subunit S & Chloroplast \\
\hline 7 & Solyc03g115980.1.1 & Geranylgeranyl reductase & Chloroplast \\
\hline 8 & Solyc10g008740.3.1 & Mg-protoporphyrin IX chelatase & Chloroplast \\
\hline 9 & Solyc10g044520.2.1 & Ferredoxin & Chloroplast \\
\hline 10 & Solyc12g013710.2.1 & Light dependent NADH:protochlorophyllide oxidoreductase 1 & Chloroplast \\
\hline 11 & Solyc02g086820.3.1 & Chloroplast carbonic anhydrase & Chloroplast \\
\hline 12 & Solyc07g066610.3.1 & Phosphoglycerate kinase & Chloroplast \\
\hline 13 & Solyc10g018300.2.1 & Transketolase & Chloroplast \\
\hline 14 & Solyc05g050970.3.1 & Transketolase & Chloroplast \\
\hline 15 & Solyc04g009030.3.1 & Glyceraldehyde-3-phosphate dehydrogenase & Chloroplast \\
\hline 16 & Solyc01g110360.3.1 & Fructose-bisphosphate aldolase & Chloroplast \\
\hline 17 & Solyc12g094640.2.1 & Glyceraldehyde-3-phosphate dehydrogenase & Chloroplast \\
\hline 18 & Solyc02g062340.3.1 & Fructose-bisphosphate aldolase & Chloroplast \\
\hline 19 & Solyc01g097460.3.1 & Ribose 5-phosphate isomerase-related family protein & chloroplast \\
\hline 20 & Solyc02g084440.3.1 & Fructose-bisphosphate aldolase & Chloroplast \\
\hline 21 & Solyc05g052600.3.1 & Sedoheptulose-1,7-bisphosphatase & Chloroplast \\
\hline 22 & Solyc12g009400.2.1 & Pyruvate dehydrogenase E1 component subunit alpha & Chloroplast \\
\hline 23 & Solyc02g091580.3.1 & Oligopeptidase A & Chloroplast \\
\hline 24 & Solyc05g050120.3.1 & Cytosolic NADP-malic enzyme & Chloroplast \\
\hline 25 & Solyc09g098120.3.1 & Oil body-associated protein $1 \mathrm{~A}$ & Chloroplast \\
\hline 26 & Solyc03g118410.3.1 & Acyl carrier protein & Chloroplast \\
\hline 27 & Solyc04g073990.3.1 & Annexin p34 & Cytoplasm \\
\hline 28 & Solyc09g090970.3.1 & Major allergen Pruar 1 & Cytoplasm \\
\hline 29 & Solyc07g005390.3.1 & Aldehyde dehydrogenase $11 \mathrm{~A} 3$ & Cytoplasm \\
\hline 30 & Solyc01g087120.3.1 & F1-ATP synthase delta subunit & Mitochondria \\
\hline 31 & Solyc02g091560.3.1 & Serine hydroxymethyltransferase & Mitochondria \\
\hline 32 & Solyc12g042920.2.1 & Cytochrome $\mathrm{cl}$, heme protein & Mitochondria \\
\hline 33 & Solyc08g065220.3.1 & Glycine decarboxylase p-protein & Mitochondria \\
\hline 34 & Solyc07g056540.3.1 & Glycolate oxidase X92888 & Peroxisome \\
\hline 35 & Solyc09g025210.3.1 & Alcohol dehydrogenase- 2 & Vacuole \\
\hline 36 & Solyc09g072560.3.1 & Legumin 11S-globulin & Vacuole \\
\hline 37 & Solyc03g005580.2.1 & 11S storage globulin & Vacuole \\
\hline 38 & Solyc09g090150.3.1 & 11S storage globulin & Vacuole \\
\hline 39 & Solyc01g110110.3.1 & Cysteine proteinase & Vacuole \\
\hline 40 & Solyc09g065470.3.1 & $7 \mathrm{~S}$ globulin & Vacuole \\
\hline 41 & Solyc1lg072380.2.1 & Vicilin-like antimicrobial peptides $2-2$ & Vacuole \\
\hline 42 & Solyc09g008770.3.1 & Late embryogenesis abundant protein, putative & Cell wall \\
\hline 43 & Solyc1lg056680.1.1 & Leucine-rich repeat receptor-like protein kinase family & Cell wall \\
\hline 44 & Solyc01g074010.3.1 & Protein kinase superfamily protein & Nucleus \\
\hline 45 & Solyc04g074550.3.1 & Cytochrome $\mathrm{c}$ oxidase subunit $6 \mathrm{~B}$ & Nucleus \\
\hline 46 & Solyc07g042440.3.1 & Peroxiredoxin & Nucleus \\
\hline 47 & Solyc01g074010.3.1 & Protein kinase superfamily protein & Nucleus \\
\hline 48 & Solyc01g080280.3.1 & Chloroplast glutamine synthetase & Chloroplast, Mitochondrion \\
\hline 49 & Solyc05g053300.3.1 & Dihydrolipoamide dehydrogenase precursor & Chloroplast, mitochondrion \\
\hline 50 & Solyc01g108600.3.1 & Presequence protease 2 & Chloroplast, mitochondrion \\
\hline 51 & Solyc09g009390.3.1 & Monodehydroascorbate reductase & Chloroplast, cytoplasm \\
\hline 52 & Solyclog082030.2.1 & 2-Cys peroxiredoxin 1 & Chloroplast, cytoplasm \\
\hline 53 & Solyc0lg106430.3.1 & Inorganic pyrophosphatase & Chloroplast, cytoplasm \\
\hline 54 & Solyc02g080810.3.1 & Aminomethyltransferase & Cytoplasm, mitochondrion \\
\hline 55 & Solyc12g088670.2.1 & Cysteine protease CYP1 & Golgi apparatus, vacuole \\
\hline 56 & Solyc02g079290.3.1 & Protein SELF PRUNING 2G & Cytoplasm, nucleus \\
\hline 57 & Solyc07g061790.3.1 & SOUL heme-binding family protein & Chloroplast, Golgi apparatus \\
\hline
\end{tabular}

Table 1. Proteins within each subcellular location group. Accession number and description from the International Tomato Annotation Group (ITAG) release version 3.0. 


\begin{tabular}{|c|c|c|c|c|c|c|c|}
\hline \multirow[b]{2}{*}{ Sl no } & \multirow[b]{2}{*}{ Acc.no } & \multirow[b]{2}{*}{ Entry name } & \multirow[b]{2}{*}{ Unique peptide } & \multicolumn{2}{|c|}{$48 \mathrm{~h}(\mathrm{FR} / \mathrm{D})$} & \multicolumn{2}{|c|}{$96 \mathrm{~h}(\mathrm{FR} / \mathrm{D})$} \\
\hline & & & & Mean & Std. error & Mean & Std. error \\
\hline 1 & \multicolumn{7}{|l|}{ Photosynthesis } \\
\hline 2 & Solyc10g006900.3.1 & $\begin{array}{l}\text { Light dependent } \\
\text { NADH:protochlorophyllide oxidoreduc- } \\
\text { tase 3 s2 }\end{array}$ & 13 & 1.21 & 0.23 & 1.09 & 0.11 \\
\hline 3 & Solyc07g044860.3.1 & psbXphotosystem II $23 \mathrm{kDa}$ protein & 8 & 1.04 & 0.18 & 1.52 & 0.17 \\
\hline 4 & Solyc07g032640.2.1 & Oxygen-evolving enhancer protein 1 & 9 & NS & NS & NS & NS \\
\hline 5 & Solyc02g079950.3.1 & $\begin{array}{l}\text { Photosystem II oxygen-evolving complex } \\
\text { protein } 3\end{array}$ & 5 & NS & NS & NS & NS \\
\hline 6 & Solyc06g060340.3.1 & Photosystem II subunit S & 3 & NS & NS & NS & NS \\
\hline 7 & Solyc06g063370.3.1 & Type I (26 kD) CP29 polypeptide & 3 & NS & NS & NS & NS \\
\hline 8 & Solyc10g044520.2.1 & Ferredoxin & 1 & NS & NS & NS & NS \\
\hline 9 & Solyc02g083810.3.1 & Ferredoxin-NADP reductase & 3 & NS & NS & NS & NS \\
\hline \multirow[t]{2}{*}{10} & Solyc01g079470.3.1 & CP12 & 1 & NS & NS & NS & NS \\
\hline & \multicolumn{7}{|c|}{ Carbon metabolism } \\
\hline 11 & Solyc05g050970.3.1 & Transketolase & 10 & 1.21 & 0.19 & 1.24 & 0.14 \\
\hline 12 & Solyc04g009030.3.1 & $\begin{array}{l}\text { Glyceraldehyde-3-phosphate dehydro- } \\
\text { genase }\end{array}$ & 8 & NS & NS & NS & NS \\
\hline 13 & Solyc01g110360.3.1 & Fructose-bisphosphate aldolase & 9 & NS & NS & NS & NS \\
\hline 14 & Solyc02g063150.3.1 & RuBP carboxylase small subunit & 6 & 1.17 & 0.13 & 1.07 & 0.24 \\
\hline 15 & Solyc12g094640.2.1 & $\begin{array}{l}\text { Glyceraldehyde-3-phosphate dehydro- } \\
\text { genase }\end{array}$ & 7 & NS & NS & NS & NS \\
\hline 16 & Solyc02g062340.3.1 & Fructose-bisphosphate aldolase & 4 & NS & NS & NS & NS \\
\hline 17 & Solyc02g084440.3.1 & Fructose-bisphosphate aldolase & 8 & NS & NS & NS & NS \\
\hline 18 & Solyc02g086820.3.1 & Chloroplast carbonic anhydrase & 5 & NS & NS & NS & NS \\
\hline 19 & Solyc07g056540.3.1 & Glycolate oxidase X92888 & 6 & NS & NS & NS & NS \\
\hline 20 & Solyc01g106430.3.1 & Inorganic pyrophosphatase & 3 & 1.52 & 0.08 & 1.11 & 0.17 \\
\hline 22 & Solyc01g080460.3.1 & Pyruvate orthophosphate dikinase & 9 & 1.23 & 0.12 & 1.06 & 0.02 \\
\hline \multirow[t]{2}{*}{23} & Solyc1lg009080.2.1 & DAHP synthase 1 precursor & 3 & NS & NS & NS & NS \\
\hline & \multicolumn{7}{|c|}{ Nitrogen assimilation, amino acid biosynthesis and protein degradation } \\
\hline 24 & Solyc02g080810.3.1 & Amino methyltransferase & 8 & 1.16 & 0.04 & 1.55 & 0.25 \\
\hline 25 & Solyc01g080280.3.1 & Chloroplast glutamine synthetase & 6 & NS & NS & NS & NS \\
\hline \multirow[t]{2}{*}{26} & Solyc02g091580.3.1 & Oligopeptidase A & 5 & NS & NS & NS & NS \\
\hline & \multicolumn{7}{|l|}{ Signaling } \\
\hline \multirow[t]{2}{*}{27} & Solyc07g061790.3.1 & SOUL heme-binding family protein & 3 & NS & NS & NS & NS \\
\hline & \multicolumn{7}{|l|}{ Storage } \\
\hline 28 & Solyc03g005580.2.1 & 11S storage globulin & 35 & 0.96 & 0.05 & 0.62 & 0.05 \\
\hline 29 & Solyc1lg072380.2.1 & Vicilin-like antimicrobial peptides $2-2$ & 11 & 1.00 & 0.03 & 0.51 & 0.07 \\
\hline 30 & Solyc01g090360.3.1 & Non-specific lipid-transfer protein & 8 & 0.64 & 0.10 & 1.02 & 0.22 \\
\hline 31 & Solyc10g075050.2.1 & Non-specific lipid-transfer protein & 6 & 0.58 & 0.11 & 0.55 & 0.19 \\
\hline 32 & Solyc02g077430.3.1 & Phospholipase A1 & 5 & 1.40 & 0.22 & 0.49 & 0.02 \\
\hline \multirow[t]{2}{*}{33} & Solyc04g007570.2.1 & GDSL esterase/lipase 6 & 1 & NS & NS & NS & NS \\
\hline & \multicolumn{7}{|l|}{ Stress and defence } \\
\hline 34 & Solyc12g094620.2.1 & Catalase & 14 & 0.92 & 0.14 & 0.81 & 0.05 \\
\hline 35 & Solyc12g010820.2.1 & Late embryogenesis abundant protein-like & 4 & NS & NS & NS & NS \\
\hline 36 & Solyc01g079820.3.1 & Peroxiredoxin & 4 & 1.27 & 0.17 & 1.05 & 0.09 \\
\hline
\end{tabular}

Table 2. List of differentially abundant proteins identified in tomato AC seedlings treated with FR light as a function of time. A representative list of proteins from the iTRAQ data (Mean) showing a differential expression pattern. Accession number and description from the International Tomato Annotation Group (ITAG) release version 3.0.

has a very different developmental pattern, which is known as skotomorphogenesis ${ }^{34}$. In skotomorphogenesis, resources are allocated towards hypocotyl elongation at the expense of cotyledon and root development. This growth strategy assures that limited seed reserves are used cautiously until they find sunlight which is a prerequisite for photoautotroph survival ${ }^{35}$.

However, our study showed that a set of proteins exhibited a limited difference in abundance between FR and dark treatment. Light independent proteins that showed no change in abundance in response to light treatment suggest that large gene expression changes are not necessarily reflected in large protein abundance changes and these proteins are developmentally regulated on a temporal scale. 
It has previously been shown that in Angiosperms photoconversion of protochlorophyllide (Pchlide) to chlorophyllide (Chlide) by the enzyme NADPH: Pchlide oxidoreductase (POR) is inefficient under FR wavelengths, and seedlings grown under prolonged FR fail to accumulate chlorophyll ${ }^{36,37}$. The phenomenon, also known as the FR block of greening response, has been characterized as a reduction of POR A (and partially of POR B) and associated damage of the membrane system of the prolamellar body ${ }^{38,39}$. However, Runge et al. ${ }^{39}$ reported that POR A expression rapidly becomes undetectable after illumination under continuous FR, whereas POR $\mathrm{B}$ expression persists throughout the greening process. Their study suggests that the two enzymes perform a unique biological function during development. In line with these observations, our results showed that there is an accumulation of POR B even in the FR-treated seedlings. Our results also reveal that FR treatment does not influence POR B accumulation, as both dark- and FR-treated seedlings showed similar levels at $48 \mathrm{~h}$, but there is an increased protein abundance at $96 \mathrm{~h}$ in both the treatment. The higher abundance of POR B at $96 \mathrm{~h}$ indicates that as under FR there is no conversion of PChl to Chl, the turnover of POR B protein is not initiated under de-etiolation under FR.

Loss of Phytochrome A results in the decreased abundance of proteins associated with primary metabolism. Being sessile organisms, plants must adjust their growth and development to the ambient light environment. Variations in light quality in the red and far-red regions of the spectrum (i.e. R: FR ratio) are sensed by the phytochromes. In response to low R: FR ratio signals, many plants exhibit shade avoidance syndrome, in anticipation of being shaded ${ }^{40}$. This process is often executed at the expense of leaf and storage organ development. Shade-avoidance syndrome provides an essential survival strategy in rapidly growing populations. Although shade avoidance may have major fitness benefits in crowded communities, the reallocation of resources towards elongation growth may lead to an increased risk of lodging and mechanical injury ${ }^{41}$. The roles of individual phytochromes in facilitating responses to low R: FR ratios have been mostly deduced from studies using mutants deficient in one or more family members. Many of these studies have confirmed the key involvement of phyB in transducing the low R: FR ratio signal, and inducing shade avoidance response ${ }^{42}$.

In contrast to other phytochromes, phyA is a light labile phytochrome, which subjects to rapid proteolytic degradation upon photoconversion to Pfr and accumulates to high levels only in etiolated seedlings ${ }^{43}$. Despite being present at reduced levels in light-grown plants, phyA performs an important role in the regulation of hypocotyl elongation in response to shade (reduced R: FR ratio). The enhanced hypocotyl elongation in phy $A$ mutant seedlings under low R: FR ratio light ${ }^{44}$, led to the suggestion that in wild-type plants, phyA action was antagonizing phyB-mediated shade avoidance by constraining hypocotyl extension. The action of phyA in constraining shade-avoidance elongation responses has been shown to be highly essential in the seedling establishment under dense natural vegetational shade ${ }^{45}$. The growth-inhibitory action of phyA in low R: FR ratio conditions can be successfully exploited to eliminate the unwanted elongation responses in more densely planted crops ${ }^{46}$.

To examine the role of PhyA in regulating primary metabolism, fri mutant seedlings were grown under continuous FR along with AC seedlings (Fig. 1A). FR light insensitive (fri) mutant of tomato harbors a base substitution in PHYA gene resulting in aberrant processing of the pre-mRNA ${ }^{47}$. The physiological characterization of the mutant seedlings revealed that they are insensitive to FR light and they exhibit loss of FR-HIR for hypocotyls inhibition. The seedlings were treated for $48 \mathrm{~h}$ and $96 \mathrm{~h}$ under FR to study the temporal regulation of protein. It is known that under continuous FR, PhyA is the prominent phytochrome molecule involved in the de-etiolation process, and loss of PHYA gene function might lead to altered protein accumulation ${ }^{37,48}$. A total of 135 statistically significant proteins were identified (Supplementary Fig. S4A) from the iTRAQ-based quantitative temporal proteomic analysis of fri mutant grown under FR (fri/FR versus AC/FR). Our analysis revealed a subset of 69 proteins common to both the time-points, while 22 and 19 different proteins were expressed exclusively in 48 and 96 h of treatment, respectively. When we examined the protein expression profile of FR treated fri mutant, we found a significant proteome alteration associated with photosynthesis, electron transfer, and carbon and nitrogen metabolism. Proteins associated with chlorophyll synthesis, ATP production, Calvin cycle, glycolysis, and TCA cycle (Fig. 2B) are severely affected in the fri mutant and showed a drastically decreased abundance on longer treatments $(96 \mathrm{~h})$ compared to the control sample. Interestingly, light-independent proteins, which are discussed in the previous session, also showed a decreased abundance in the fri mutant (Fig. 2B and Table 3).

Collectively, global proteome analysis provides support for several generalizations. The data confirms that most of the proteins exhibit significant responses to FR in the control relative to fri mutant. Thus, these data furnish strong verification that the genes identified here are regulated by PhyA in response to the FR light signal. Moreover, our results showed that the majority of genes begin to respond to the light signal after $48 \mathrm{~h}$ and reach their maximum response within $96 \mathrm{~h}$. The results confirm that the major part of the cellular functions underlying the de-etiolation process is established after $48 \mathrm{~h}$ of the FR treatment.

The global proteomics analysis revealed alterations among various protein groups and for a better understanding of their functions, they have been categorized into small sub-groups, which are discussed in detail hereafter.

Photosynthesis light reaction The loss of PhyA resulted in an overall decrease in the abundance of photosynthetic proteins, which could be due to the involvement of PhyA in the biosynthesis of chlorophyll and other associated proteins. The development of chloroplasts and their preparation for the photosynthetic function is regarded as some of the prominent features of the seedling establishment during early development. Several studies have revealed that Phys are important regulators of the synthesis of photosynthetic pigment ${ }^{49}$. The R-light treatment has been shown to induce the chlorophyll synthesis ${ }^{50}$, while depletion of phytochromes in the R-grown seedlings leads to concomitant reductions in chlorophyll levels ${ }^{51}$.

Proteins like light-dependent NADH: protochlorophyllide oxidoreductase 1 or Por isoform (Solyc12g013710.2.1), light-dependent NADH: protochlorophyllide oxidoreductase 3 or PorB (Solyc10g006900.3.1), Geranylgeranyl reductase (Solyc03g115980.1.1), and Mg-protoporphyrin IX chelatase 


\begin{tabular}{|c|c|c|c|c|c|c|c|}
\hline \multirow[b]{2}{*}{ Sl.No } & \multirow[b]{2}{*}{ Acc.no } & \multirow[b]{2}{*}{ Entry name } & \multirow[b]{2}{*}{ Unique peptide } & \multicolumn{2}{|c|}{$48 \mathrm{~h}(\mathrm{MUT} / \mathrm{AC})$} & \multicolumn{2}{|c|}{$96 \mathrm{~h}(\mathrm{MUT} / \mathrm{AC})$} \\
\hline & & & & Mean & Std. error & Mean & Std. error \\
\hline & \multicolumn{7}{|l|}{ Photosynthesis } \\
\hline 1 & Solyc10g006900.3.1 & $\begin{array}{l}\text { Light dependent } \\
\text { NADH:protochlorophyllide oxidoreduc- } \\
\text { tase } 3 \text { s2 }\end{array}$ & 5 & 0.25 & 0.04 & 0.33 & 0.05 \\
\hline 2 & Solyc07g044860.3.1 & psbXphotosystem II 23 kDa protein & 8 & 0.28 & 0.04 & 0.31 & 0.06 \\
\hline 3 & Solyc12g013710.2.1 & Oxygen-evolving enhancer protein 1 & 4 & 0.70 & 0.15 & 0.33 & 0.01 \\
\hline 4 & Solyc07g032640.2.1 & Oxygen-evolving enhancer protein & 2 & 0.24 & 0.02 & 0.42 & 0.07 \\
\hline 5 & Solyc02g065400.3.1 & $\begin{array}{l}33 \mathrm{kDa} \text { precursor protein of oxygen- } \\
\text { evolving complex }\end{array}$ & 2 & 0.25 & 0.03 & 0.34 & 0.05 \\
\hline 6 & Solyc02g079950.3.1 & $\begin{array}{l}\text { Photosystem II oxygen-evolving complex } \\
\text { protein } 3\end{array}$ & 5 & 0.24 & 0.02 & 0.33 & 0.10 \\
\hline 7 & Solyc06g060340.3.1 & Photosystem II subunit S & 3 & 0.25 & 0.03 & 0.40 & 0.14 \\
\hline 8 & Solyc06g063370.3.1 & Type I (26 kD) CP29 polypeptide & 3 & 0.17 & 0.04 & 0.20 & 0.05 \\
\hline 9 & Solyc06g072540.1.1 & ATP synthase subunit alpha, chloroplastic & 2 & 0.28 & 0.02 & 0.46 & 0.09 \\
\hline 10 & Solyc01g087120.3.1 & F1-ATP synthase delta subunit & 4 & 0.85 & 0.11 & 0.60 & 0.02 \\
\hline 11 & Solyc03g115980.1.1 & Geranylgeranyl reductase & 4 & 0.52 & 0.04 & 0.41 & 0.10 \\
\hline 12 & Solyc10g084040.2.1 & $\begin{array}{l}\text { Thylakoid lumenal } 15.0 \mathrm{kDa} \text { protein } 2 \text {, } \\
\text { chloroplastic }\end{array}$ & 3 & 0.44 & 0.04 & 0.59 & 0.08 \\
\hline 13 & Solyc10g008740.3.1 & Mg-protoporphyrin IX chelatase & 4 & 0.65 & 0.05 & 0.43 & 0.11 \\
\hline \multirow[t]{2}{*}{14} & Solyc10g044520.2.1 & Ferredoxin & 1 & 0.39 & 0.01 & 0.33 & 0.02 \\
\hline & \multicolumn{7}{|c|}{ Carbon metabolism } \\
\hline 15 & Solyc07g066610.3.1 & Phosphoglycerate kinase & 14 & 0.25 & 0.03 & 0.50 & 0.07 \\
\hline 16 & Solyc10g086580.2.1 & $\begin{array}{l}\text { Ribulose bisphosphate carboxylase/oxyge- } \\
\text { nase activase }\end{array}$ & 15 & 0.12 & 0.01 & 0.30 & 0.05 \\
\hline 17 & Solyc10g018300.2.1 & Transketolase & 8 & 0.27 & 0.01 & 0.43 & 0.08 \\
\hline 18 & Solyc05g050970.3.1 & Transketolase & 8 & 0.50 & 0.05 & 0.68 & 0.14 \\
\hline 19 & Solyc04g009030.3.1 & $\begin{array}{l}\text { Glyceraldehyde-3-phosphate dehydro- } \\
\text { genase }\end{array}$ & 3 & 0.23 & 0.01 & 0.27 & 0.04 \\
\hline 20 & Solyc01g110360.3.1 & Fructose-bisphosphate aldolase & 5 & 0.46 & 0.11 & 0.56 & 0.15 \\
\hline 21 & Solyc05g053300.3.1 & $\begin{array}{l}\text { Dihydrolipoamide dehydrogenase precur- } \\
\text { sor }\end{array}$ & 6 & 0.67 & 0.06 & 0.61 & 0.08 \\
\hline 22 & Solyc02g063150.3.1 & RuBP carboxylase small subunit & 2 & 0.34 & 0.07 & 0.43 & 0.18 \\
\hline 23 & Solyc12g094640.2.1 & $\begin{array}{l}\text { Glyceraldehyde-3-phosphate dehydro- } \\
\text { genase }\end{array}$ & 5 & 0.17 & 0.03 & 0.41 & 0.06 \\
\hline 24 & Solyc02g062340.3.1 & Fructose-bisphosphate aldolase & 2 & 0.18 & 0.01 & 0.33 & 0.02 \\
\hline 25 & Solyc01g097460.3.1 & $\begin{array}{l}\text { Ribose } 5 \text {-phosphate isomerase-related } \\
\text { family protein }\end{array}$ & 4 & 0.43 & 0.04 & 0.51 & 0.10 \\
\hline 26 & Solyc02g084440.3.1 & Fructose-bisphosphate aldolase & 5 & 0.33 & 0.02 & 0.40 & 0.10 \\
\hline 27 & Solyc02g086820.3.1 & Chloroplast carbonic anhydrase & 5 & 0.16 & 0.01 & 0.56 & 0.21 \\
\hline 28 & Solyc07g056540.3.1 & Glycolate oxidase X92888 & 6 & 0.15 & 0.02 & 0.33 & 0.04 \\
\hline 29 & Solyc05g050120.3.1 & Cytosolic NADP-malic enzyme & 5 & 0.88 & 0.09 & 0.62 & 0.14 \\
\hline 30 & Solyc05g052600.3.1 & Sedoheptulose-1,7-bisphosphatase & 4 & 0.17 & 0.02 & 0.40 & 0.06 \\
\hline 31 & Solyc12g009400.2.1 & $\begin{array}{l}\text { Pyruvate dehydrogenase E1 component } \\
\text { subunit alpha }\end{array}$ & 3 & 0.55 & 0.02 & 0.67 & 0.10 \\
\hline 32 & Solyc01g106430.3.1 & Inorganic pyrophosphatase & 3 & 0.66 & 0.05 & 0.50 & 0.07 \\
\hline 33 & Solyc07g005390.3.1 & aldehyde dehydrogenase $11 \mathrm{~A} 3$ & 2 & 0.38 & 0.04 & 0.51 & 0.04 \\
\hline \multirow[t]{2}{*}{34} & Solyc10g047430.1.1 & $\begin{array}{l}\text { LOW QUALITY:Ribulose bisphosphate } \\
\text { carboxylase large chain }\end{array}$ & 2 & 0.38 & 0.06 & 0.36 & 0.03 \\
\hline & \multicolumn{7}{|c|}{ Nitrogen assimilation, amino acid biosynthesis and protein degradation } \\
\hline 35 & Solyc02g091560.3.1 & Serine hydroxymethyltransferase & 9 & 0.17 & 0.01 & 0.33 & 0.08 \\
\hline 36 & Solyc08g065220.3.1 & Glycine decarboxylase p-protein & 11 & 0.33 & 0.06 & 0.56 & 0.04 \\
\hline 37 & Solyc01g009990.3.1 & Peptidyl-prolyl cis-trans isomerase & 5 & 0.72 & 0.12 & 0.45 & 0.10 \\
\hline 38 & Solyc02g080810.3.1 & Aminomethyltransferase & 8 & 0.39 & 0.01 & 0.55 & 0.09 \\
\hline 39 & Solyc01g080280.3.1 & Chloroplast glutamine synthetase & 6 & 0.37 & 0.05 & 0.34 & 0.01 \\
\hline 40 & Solyc01g108600.3.1 & Presequence protease 2 & 6 & 0.64 & 0.03 & 0.53 & 0.08 \\
\hline 41 & Solyc12g088670.2.1 & Cysteine protease CYP1 & 4 & 0.37 & 0.04 & 0.38 & 0.06 \\
\hline 42 & Solyc02g091580.3.1 & Oligopeptidase A & 5 & 0.57 & 0.07 & 0.74 & 0.05 \\
\hline \multirow[t]{2}{*}{43} & Solyc01g110110.3.1 & Cysteine proteinase & 4 & 2.19 & 0.53 & 0.65 & 0.04 \\
\hline & \multicolumn{7}{|l|}{ Stress and defense } \\
\hline
\end{tabular}




\begin{tabular}{|c|c|c|c|c|c|c|c|}
\hline \multirow[b]{2}{*}{ Sl.No } & \multirow[b]{2}{*}{ Acc.no } & \multirow[b]{2}{*}{ Entry name } & \multirow[b]{2}{*}{ Unique peptide } & \multicolumn{2}{|c|}{48 h (MUT/AC) } & \multicolumn{2}{|c|}{96 h (MUT/AC) } \\
\hline & & & & Mean & Std. error & Mean & Std. error \\
\hline 44 & Solyc09g008770.3.1 & $\begin{array}{l}\text { Late embryogenesis abundant protein, } \\
\text { putative }\end{array}$ & 18 & 1.58 & 0.22 & 1.09 & 0.17 \\
\hline 45 & Solyc09g090970.3.1 & Major allergen Pruar 1 & 10 & 1.58 & 0.43 & 1.71 & 0.21 \\
\hline 46 & Solyc09g009390.3.1 & Monodehydroascorbate reductase & 8 & 0.56 & 0.05 & 0.64 & 0.09 \\
\hline 47 & Solyc10g082030.2.1 & 2-Cys peroxiredoxin 1 & 3 & 0.55 & 0.03 & 0.64 & 0.03 \\
\hline 48 & Solyc04g073990.3.1 & Annexin p34 & 10 & 1.94 & 0.28 & 1.44 & 0.23 \\
\hline 49 & Solyc06g048840.3.1 & Late embryogenesis abundant protein & 7 & 1.45 & 0.57 & 0.46 & 0.04 \\
\hline \multirow[t]{2}{*}{50} & Solyc07g042440.3.1 & Peroxiredoxin & 5 & 0.57 & 0.03 & 0.53 & 0.06 \\
\hline & \multicolumn{7}{|l|}{ Signalling } \\
\hline 51 & Solyc1lg056680.1.1 & $\begin{array}{l}\text { Leucine-rich repeat receptor-like protein } \\
\text { kinase family }\end{array}$ & 4 & 0.57 & 0.09 & 0.45 & 0.01 \\
\hline 52 & Solyc01g074010.3.1 & Protein kinase superfamily protein & 1 & 0.47 & 0.08 & 0.73 & 0.16 \\
\hline \multirow[t]{2}{*}{53} & Solyc07g061790.3.1 & SOUL heme-binding family protein & 3 & 0.27 & 0.02 & 0.31 & 0.05 \\
\hline & \multicolumn{7}{|l|}{ Storage } \\
\hline 54 & Solyc09g025210.3.1 & Alcohol dehydrogenase-2 & 35 & 2.27 & 0.26 & 1.24 & 0.07 \\
\hline 55 & Solyc09g072560.3.1 & Legumin 11S-globulin & 25 & 2.63 & 0.88 & 1.19 & 0.07 \\
\hline 56 & Solyc03g005580.2.1 & 11S storage globulin & 34 & 2.09 & 0.38 & 1.17 & 0.08 \\
\hline 57 & Solyc09g090150.3.1 & 11S storage globulin & 23 & 2.12 & 0.37 & 1.58 & 0.25 \\
\hline 58 & Solyc09g065470.3.1 & $7 \mathrm{~S}$ globulin & 14 & 3.66 & 1.19 & 0.99 & 0.18 \\
\hline 59 & Solyc1lg072380.2.1 & Vicilin-like antimicrobial peptides $2-2$ & 11 & 2.52 & 0.51 & 1.09 & 0.14 \\
\hline 60 & Solyc09g098120.3.1 & Oil body-associated protein $1 \mathrm{~A}$ & 5 & 1.64 & 0.21 & 1.05 & 0.03 \\
\hline \multirow[t]{2}{*}{61} & Solyc03g118410.3.1 & Acyl carrier protein & 2 & 0.24 & 0.01 & 0.35 & 0.03 \\
\hline & \multicolumn{7}{|c|}{ Meristem development/branching } \\
\hline \multirow[t]{2}{*}{62} & Solyc02g079290.3.1 & Protein SELF PRUNING 2G & 3 & 1.84 & 0.33 & 0.85 & 0.12 \\
\hline & \multicolumn{7}{|c|}{ Hormone signaling (GA) } \\
\hline 63 & Solyc01g006580.3.1 & $\begin{array}{l}\text { 2-oxoglutarate-dependent dioxygenase- } \\
\text { related family protein }\end{array}$ & 3 & 0.58 & 0.09 & 0.38 & 0.03 \\
\hline
\end{tabular}

Table 3. List of differentially expressed proteins in fri mutant at different time points. A representative list of proteins from the iTRAQ data (Mean) showing a differential expression pattern. Accession number and description from the International Tomato Annotation Group (ITAG) release version 3.0.

(Solyc10g008740.3.1), which are involved in chlorophyll biosynthetic process, exhibited a decreased abundance in the mutant (Fig. 2B). The light-dependent reaction is performed by several intrinsic membrane-protein complexes named photosystem I (PSI), photosystem II (PSII), cytochrome (cyt) b6f. complex, and ATP synthase s2 $^{52}$ Several proteins that are identified to be the components of the reaction center of PS-II (photosystem-II), Oxygen evolving complex, ATP synthase subunit, etc. showed a decrease in their accumulation in the mutant as compared to their control when treated under FR (Fig. 2B).

Carbon assimilation and carbohydrate metabolism Proteins involved in carbon assimilation and carbohydrate metabolism showed a decreased abundance in the mutant grown under FR when compared to AC seedlings grown under the same condition. Rubisco (large and small subunits) and Rubisco activase exhibited a decreased abundance in the fri mutant compared to AC seedlings treated under FR. The chloroplast enzyme sedoheptulose 1,7-bisphosphatase (SBPASE), a key enzyme in the Calvin cycle, catalyzes the dephosphorylation of sedoheptulose-1,7-bisphosphate to sedoheptulose-7-phosphate and also involved in the regulation of the carbon flow ${ }^{53-55}$, showed a decrease in abundance in the mutant under continuous FR treatment when compared to AC seedlings. Other Calvin cycle enzymes like phosphoglycerate kinase and Fructose 1.6-bisphosphate aldolase (Solyc02g062340.3.1) also exhibited a decreased abundance when treated under FR light compared to the control seedlings (Fig. 2B and Table 3).

The FR-grown mutant seedlings displayed a reduced plastidial glycolysis pathway with a reduced abundance of glycolytic enzymes such as Fructose 1,6-bisphosphate aldolase (Solyc02g084440.3.1), phosphoglycerate kinase catalyzes the phosphorylation of 3-phosphoglycerate to 1,3-diphosphoglycerate, and Glyceraldehyde-3-P dehydrogenase (GAPC) compared to the control seedlings grown under the same condition. Glyceraldehyde-3-P dehydrogenase, a key enzyme in energy metabolism, mediates the conversion of glyceraldehyde-3-P to 1,3-bisphosphoglycerate, found to be involved in several cellular functions apart from glycolysis.

In our study pyruvate dehydrogenase E1 component subunit alpha (Solyc12g009400.2.1), showed a decline in their abundance in the mutant seedlings compared to the control seedlings when grown under FR. Proteins of pyruvate dehydrogenase complex, including dihydrolipoyl dehydrogenase and dihydrolipoamide dehydrogenase precursor too, exhibited a decreased level of abundance in the mutant seedlings grown under FR light compared to their corresponding controls (Fig. 2B and Table 3). The loss of phytochrome results in retarded growth, and in such cases, resources are allocated towards resilience than growth, and this strategy is based on changing the metabolism at a fundamental level ${ }^{8,11}$. Yang et al. ${ }^{8}$ performed comprehensive metabolomics and gene expression 


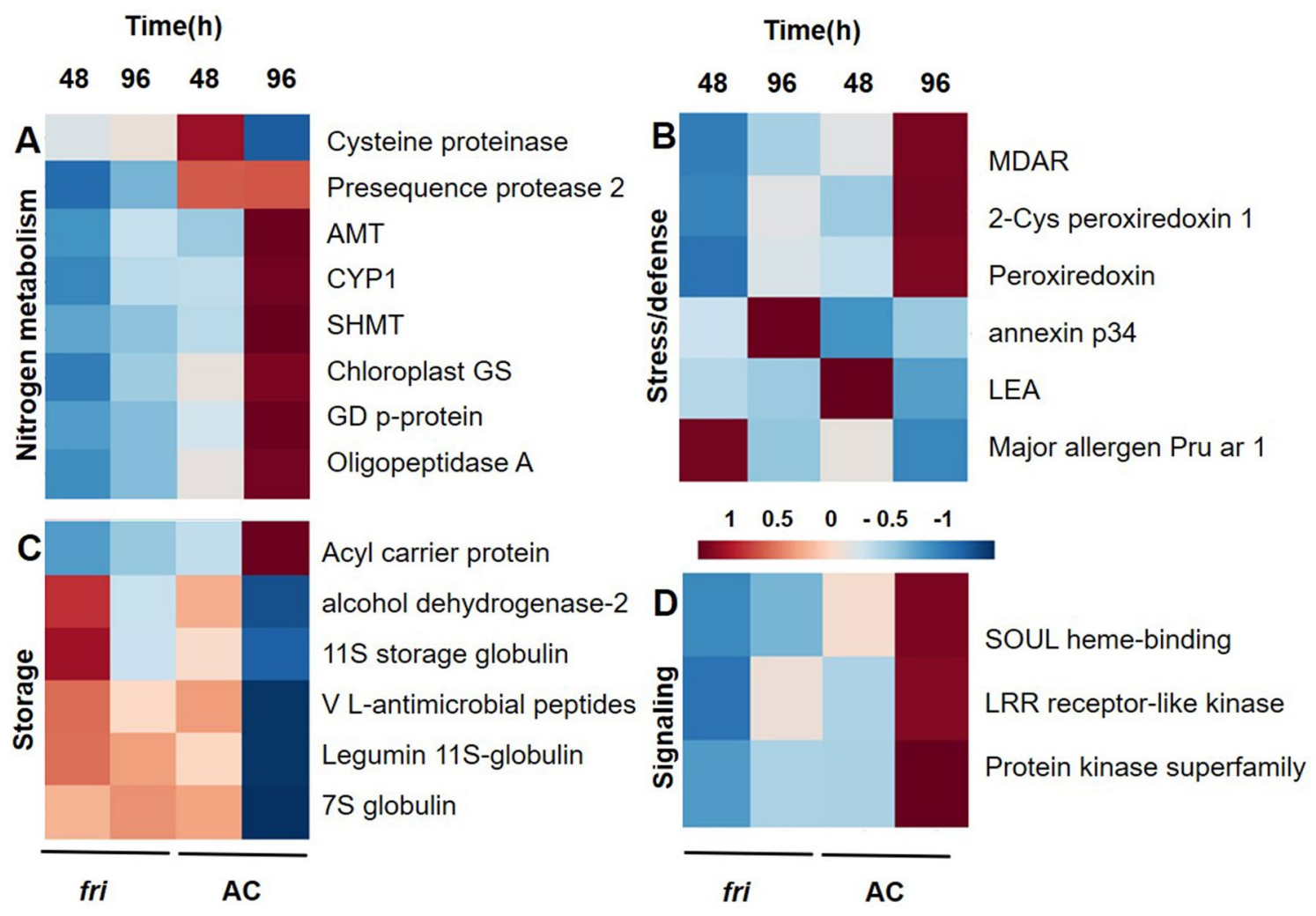

Figure 3. PhyA regulated proteins associated with nitrogen metabolism, storage, and stress/defense metabolic pathways. Heat map showing the fold ratio of differentially altered proteins involved in nitrogen metabolism (A), stress/defense (B) storage (C), and signaling (D) metabolic pathways in fri mutant in comparison to AC seedlings under FR irradiation. MDAR-Monodehydroascorbate reductase; Chloroplast GS-chloroplast glutamine synthetase; AMT-Amino methyltransferase; SHMT-Serine hydroxymethyltransferase; GD p-proteinglycine decarboxylase p-protein; cysteine protease CYP1; LEA-Late embryogenesis abundant protein; LRRLeucine-rich repeat.

studies of Arabidopsis thaliana to determine the role of Phytochrome in central metabolism. The study revealed that loss of phytochrome impacts core metabolism. Han et al. ${ }^{56}$ reported that PhyA and PhyB signaling play important roles in the regulation of carbon metabolism in plant leaves, being influenced not only by the quantity of light but also the quality. Carlson et al. ${ }^{57}$ investigated the transcriptomic and gel-based proteomic profile of tomato seedlings during the transition from dark to light (red light) and found that PhyA regulates carbon flux through major primary metabolic pathways. A study by Fox et al. ${ }^{58}$ has revealed the contribution of various photoreceptors in the regulation of proteins involved in chloroplast metabolism and the Calvin cycle, including Rubisco and Rubisco activase. The quadruple phyA;phyB;cry1;cry2 mutant exhibited a reduced $\mathrm{CO}_{2}$ fixation and impaired activity of the Calvin cycle proteins with decreased levels of chlorophyll. These data suggest that Phy and Cry signaling has a crucial role in photosynthesis and carbon fixation using the Calvin cycle. Our data indicate that PhyA action is important in regulating carbon assimilation, and loss of the photoreceptors results in a concomitant decrease in the carbon assimilation efficiency and alteration in carbon flux.

Amino acid biosynthesis and protein degradation The photosynthetically assimilated carbon is distributed into different metabolic pathways to either provide energy for growth and development or to synthesize amino acids for protein synthesis. Evidence suggests that phytochrome signaling has sizable effects on nitrogen metabolism ${ }^{7,50,56}$. Loss of PhyA resulted in an alteration in the nitrogen metabolism and both amino acid biosynthesis and protein degradation processes were de-regulated in mutant seedling grown under FR. Overall, eight proteins associated with nitrogen metabolism were dysregulated in the mutant. Among these proteins, chloroplast glutamine synthetase (GS) (Solyc01g080280.3.1), Serine hydroxymethyltransferase (SHMT) (Solyc02g091560.3.1), glycine decarboxylase p-protein (GDC) (Solyc08g065220.3.1), and amino methyltransferase (Solyc02g080810.3.1) displayed a decrease in abundance compared to the control seedling when treated under FR (Fig. 3 and Table 3). GS is a key assimilatory enzyme for ammonia ${ }^{59}$, primarily responsible for scavenging ammonia, a highly reactive and cytotoxic metabolite, and converts it to glutamine ${ }^{60}$. SHMTs, along with GDC (glycine decarboxylase complex), being involved in the transfer of hydroxymethyl of serine to typically polyglutamylated tetrahydrofolate producing Gly and 5,10-methylene $\mathrm{THF}^{61}$, while amino methyltransferase is involved in the glycine catabolism.

Protein proteolysis is indispensable for many plant signal transduction pathways and regulates the developmental stages of a plant by removing harmful or damaged proteins and supply cells with amino acids ${ }^{62}$. Proteases are thus the major players in the maintenance of cell homeostasis. Additionally, proteases also 
perform a regulatory role in a variety of processes that are essential for growth, development, reproduction, immune response, embryogenesis, photosynthesis, programmed cell death (PCD), etc ${ }^{63}$. Our results showed dysregulation of several proteases in the mutant grown under FR compared to the control. Cysteine proteinase (Solyc01g110110.3.1) showed a decrease in its accumulation in the mutant during early (48 h) treatment under FR when compared to the wild type at this time point, but continuous treatment in FR resulted in a 1.9fold increase in the abundance. However, other proteases such as cysteine protease CYP1(Solyc12g088670.2.1), presequence protease 2 (Solyc01g108600.3.1), and oligopeptidase A (Solyc02g091580.3.1) showed diminished accumulation in the mutant in both the time points of treatment compared to the control seedlings. Peptidylprolyl cis-trans isomerase (Solyc01g009990.3.1) which is involved in protein folding also showed decrease in its abundance ${ }^{64}$ compared to control seedlings when treated under FR (Fig. 3, and Table 3). As carbon metabolism was found to be severely affected in the mutant, there could be a possibility of inadequate reduced carbon in the cell. This could be one of the reasons why most of the proteins associated with nitrogen metabolism showed a decreased abundance in the mutant. However, the exact role of PhyA in regulating nitrogen metabolism needs to be investigated further.

Storage protein During seed germination, storage proteins are degraded and act as a source of amino acid, while storage lipids are mobilized to deliver an energy source for the developing seedlings ${ }^{23,65}$. Developing seedlings allocate their nutritional reserves, which include storage proteins and lipids, for hypocotyl extension, and develop machinery for photosynthesis. Among the 8 differentially expressed proteins, all the proteins were found to exhibit an increased accumulation in the mutant when compared to the control seedlings. Previous studies revealed that globulin mobilization becomes evident only after $48-72 \mathrm{~h}$ imbibition ${ }^{66}$. Globulins are broken down in the protein bodies by proteinases that are synthesized in RER (rough endoplasmic reticulum). In our study, seed storage proteins like 7S globulin (Solyc09g065470.3.1) and 11S Globulins (Solyc03g005580.2.1, Solyc09g090150.3.1) were found to be accumulated in the phyA mutant after $96 \mathrm{~h}$ of FR treatment when compared to the control seedlings at this time point. Similarly, vicilins (Solyc09g082340.2.1, Solyc11g072380.2.1) and legumin (Solyc09g072560.3.1) that are shown to be expressed in developing seedlings showed a similar trend. Oil body-associated protein (Solyc11g072380.2.1), is storage associated protein involved in accumulating nutrients and lipid; and protein trafficking between organelles ${ }^{67}$, which also showed an increase in abundance compared to the control seedlings (Fig. 3 and Table 3).

The data suggests a slow breakdown of storage protein in the fri mutant ${ }^{57}$ and it could be an indication of the absence of light-dependent development in phytochrome mutant as PhyA is the primary photoreceptor responsible for perceiving and mediating various responses to FR light ${ }^{68-70}$. In control seedling, most of the sugars are consumed after $96 \mathrm{~h}$, under FR. As phyA mutant under FR exhibits skotomorphogenesis, there is a possible conversion of sugars into storage material instead of converting into fatty acids as in photomorphogenesis ${ }^{50}$. The decreased abundance of an acyl carrier protein (Solyc03g118410.3.1) compared to the control seedlings, a major protein involved in fatty acid synthesis ${ }^{71}$, suggests an absence of sugar conversion in the mutant.

Stress and defense An appropriate light environment is a critical requirement for the establishment of proper resistance responses in defense responses ${ }^{72}$. Several defense and stress responses in plant species like rice and Arabidopsis were identified as light-dependent ${ }^{73-76}$, and studies suggest that light could regulate defense response either through light-driven chemical reaction or through downstream light-responsive signaling pathways ${ }^{72}$. Previous microarray studies ${ }^{6,77}$ demonstrated that the expression of many plant defense genes is controlled by the activity of phytochromes.

In the present study, seven stress and defense-related proteins were differentially expressed in fri mutant seedlings compared to control seedlings, including Late embryogenesis abundant protein, putative (Solyc09g008770.3.1), annexin p34 (Solyc04g073990.3.1), Major allergen Pruar 1 (Solyc09g090970.3.1), Monodehydroascorbate reductase (Solyc09g009390.3.1), 2-Cys peroxiredoxin 1 (Solyc10g082030.2.1), Peroxiredoxin (Solyc07g042440.3.1), Late embryogenesis abundant protein (Solyc06g048840.3.1) and GDSL esterase (Solyc05g013690.3.1). Among them, Monodehydroascorbate reductase, Peroxiredoxin, and 2-Cys peroxiredoxin exhibited a decrease in abundance, while other proteins showed an increase in their abundance compared to control seedlings (Fig. 3 and Table 3 ).

Late embryogenesis protein has been described for responding to abiotic stress ${ }^{78}$, while GDSL esterase function in response to both biotic and abiotic stress ${ }^{79}$ 2-Cys peroxiredoxin 1 has been proven to protect the plant cells from oxidative damage ${ }^{80}$. In Arabidopsis, annexin group proteins act as a target for calcium signals and play a major role in stress response ${ }^{81}$. Monodehydroascorbate reductase is one of the key antioxidant enzymes involved in the scavenging of reactive oxygen species ${ }^{82}$. Peroxiredoxins (Prx) employ a thiol-based catalytic mechanism to reactive oxygen species and are major components of the antioxidant defense system in higher plants. Differential regulation of stress and defense-related proteins in the mutant indicated the involvement of PhyA in the stress-responsive process during tomato seedling's early development, but the underlying mechanism needs to be further examined.

Photorespiration Light plays a significant role in the development of photorespiratory pathways ${ }^{83}$. However, the exact mechanism by which the phytochromes control photorespiration is not completely known. Photorespiratory pathways are meant for recycling the by-product of photosynthetic carbon assimilation, 2-phosphoglycolate back to ribulose 1,5-bisphosphate and it is an indispensable process in oxygenic photosynthesis ${ }^{84,85}$.

The proteomics data revealed a decreased abundance of proteins involved in photorespiration compared to their corresponding control seedlings. Glycolate oxidase, one of the key enzymes mediates photorespiratory metabolism is shown to be reduced its abundance in fri mutant (Fig. 2B and Table 3). Moreover, expression of both mitochondrial enzymes glycine decarboxylase complex and serine hydroxy methyltransferase ${ }^{18,86}$, which seems to be directly involved in photorespiration, showed a significant decrease in the accumulation in the mutant compared to the control seedlings, which is discussed in the previous section (Fig. 3 and Table 3). Our 
findings suggest that photorespiration in FR condition is regulated by PhyA and loss of PhyA activity may decrease the photorespiration rate.

Other proteins and pathways Proteins such as SOUL heme-binding family protein (Solyc07g061790.3.1) and leucine-rich repeat receptor-like protein kinase family (Solyc11g056680.1.1) that participate in various signaling pathways were shown to be deregulated in the mutant under FR treatment. In Arabidopsis, AtHBP2 was identified as a phytochrome A-induced transcript that responds to light during de-etiolation ${ }^{87}$. AtHBP2 encodes a SOUL protein and is proposed to have a role as a cytosolic tetrapyrrole-carrier protein ${ }^{88}$. Leucine-rich repeat receptor-like protein kinase family (LRR-RLK) are important mediators of cell-cell communication to transmit developmental cues and environmental stimuli and are also involved in defense/resistance response against pathogens ${ }^{89-91}$. The protein abundance of 2-oxoglutarate-dependent dioxygenase (2-ODD, Solyc01g006580.3.1) that is involved in the synthesis of plant hormones such as ethylene, GA, and flavonoids ${ }^{92,93}$ was found to be decreased compared to the control. Previous reports suggest that active phytochrome regulates the synthesis of gibberellin (GA), which promotes germination ${ }^{94,95}$. Differential regulation of 2-ODD shows the involvement of PhyA in regulating the hormone biosynthesis (Table 3 ).

PhyA regulates protein abundance in the dark. To understand the specific role of PhyA during skotomorphogenesis, we profiled the proteome of dark-grown AC and fri seedling. A total of 36 statistically significant proteins were identified (Supplementary Fig. S5) from the iTRAQ-based quantitative temporal proteomic analysis of fri mutant grown under dark (fri/D versus AC/D). From these, 13 proteins were further selected based on the fold ratio values ( $\geq 1.5$ fold up-regulation or $\leq 0.66$ fold down-regulation) and biological relevance. Our results showed an alteration in the abundance number of proteins involved in photosynthesis, carbon assimilation, stress/ defense, and storage.

Proteins that are involved in photosynthesis and carbon assimilation such as PorB, Por isoform, PGK, Mgprotoporphyrin IX chelatase, and RuBP carboxylase small subunit exhibited a decrease in abundance in fri mutant when grown under dark compared to the control. Interestingly, PorB, PGK, and RuBP carboxylase small subunit proteins were found to be light-independent proteins (that we discussed previously in the manuscript) (Supplementary Fig. S5). Our results suggest the possibility of a PhyA action in the dark and that these proteins are under positive regulation of PhyA. We also found an increased accumulation of storage proteins such as Oil body-associated protein 1A and Legumin 11S-globulin in the mutant compared to the control when grown under dark. Storage proteins are generally expressed in the developing seeds and stored until the onset of photosynthesis ${ }^{96}$. The increased abundance of storage proteins in the mutant under dark indicates the slow breakdown of these proteins compared to control seedlings. Interestingly several proteins associated with stress/ defense response such as LEA, Glutathione S-transferase, Major allergen Pru, and 2-Cys peroxiredoxin displayed a differential abundance in the mutant compared to AC seedling under dark.

As suggested by a number of mutant studies, the longer hypocotyl in phyA mutant in the dark when compared to their isogenic WT lines ${ }^{4,37}$, which indicates that phyA also functions in the dark. Previous reports propose that active phyA in the developing seed or in the fruit of the parent might induce downstream signaling and that would be active in germinating seed or seedling. Suppression of ABSCISIC ACID INSENSITIVE3 (ABI3) expression is normally mediated by seed-activated phyB and the absence of seed activated phyB in the mutant seedling resulted in an elevated level ABI3 in dark-grown Arabidopsis phyB seedlings ${ }^{97}$. In another word, lightactivated phyA-mediated signaling occurred during seed development or in the parent plant is propagated to the germinating seed and seedling through an intermediary, such as ABI3. Although our study does not show the presence of an intermediate like ABI3, our results indicate that a PhyA is required for the expression of some of the light-independent proteins, and loss of PhyA resulted in decreased abundance of these proteins. Differential protein abundance in the phy A mutant compared to control seedlings grown in the dark strongly support the broad range of phyA's function such as regulation of carbon flux, stress/defense, and conversion of storage proteins in dark-grown seedlings.

PhyA mediated signaling regulates a large number of chloroplast associated proteins. One of the important goals of proteomics is to identify the functions of proteins in various cellular organelles and pathways. The identification of subcellular locations of proteins can furnish valuable insights for revealing their functions. Additionally, this information can be explored to understand how each protein interacts with others in cellular network systems. Overall, we used 57 proteins from our study, that are found to be statistically significant in various comparisons discussed previously in the manuscript, to further understand their subcellular localization pattern. The subcellular localization of these proteins was assessed using Plant-mPLoc. Our results showed that $45 \%$ of the proteins are predicted to be targeted to the chloroplast, $12.08 \%$ to the vacuole, $7.01 \%$ to mitochondria and nucleus, $5.26 \%$ to the cytoplasm, $3.5 \%$ to the cell wall, and $1.75 \%$ were targeted to the peroxisome. We also observed that $17.54 \%$ of the total proteins were present in more than one subcellular location (Table 1).

Most of the proteins involved in chlorophyll synthesis, photosynthesis, Calvin cycle, plastidial glycolysis, and some of the proteins that are involved in amino acid metabolism and fatty acid synthesis are targeted to the chloroplast. Storage proteins and proteases were assembled in the vacuole. In mitochondria, many of the proteins associated with nitrogen metabolism were accumulated, while in the nucleus, proteins associated with signaling were found. Defense/stress-related proteins were assembled in the cytoplasm (Table 1 and Fig. 5).

Upon absorption of red light, activated Phytochromes are translocated from the cytoplasm to the nucleus, where they inhibit the activity of several transcription factors, and thereby induce genome-wide changes in the transcription of target genes and mediate various light responses ${ }^{98,99}$. A recent study revealed that phytochrome controls not only the transcription but also the alternative splicing to mediate light responses in $A$. thaliana $a^{100}$. The genome-wide changes in alternative promoter selection modulate protein localization, thereby allowing 


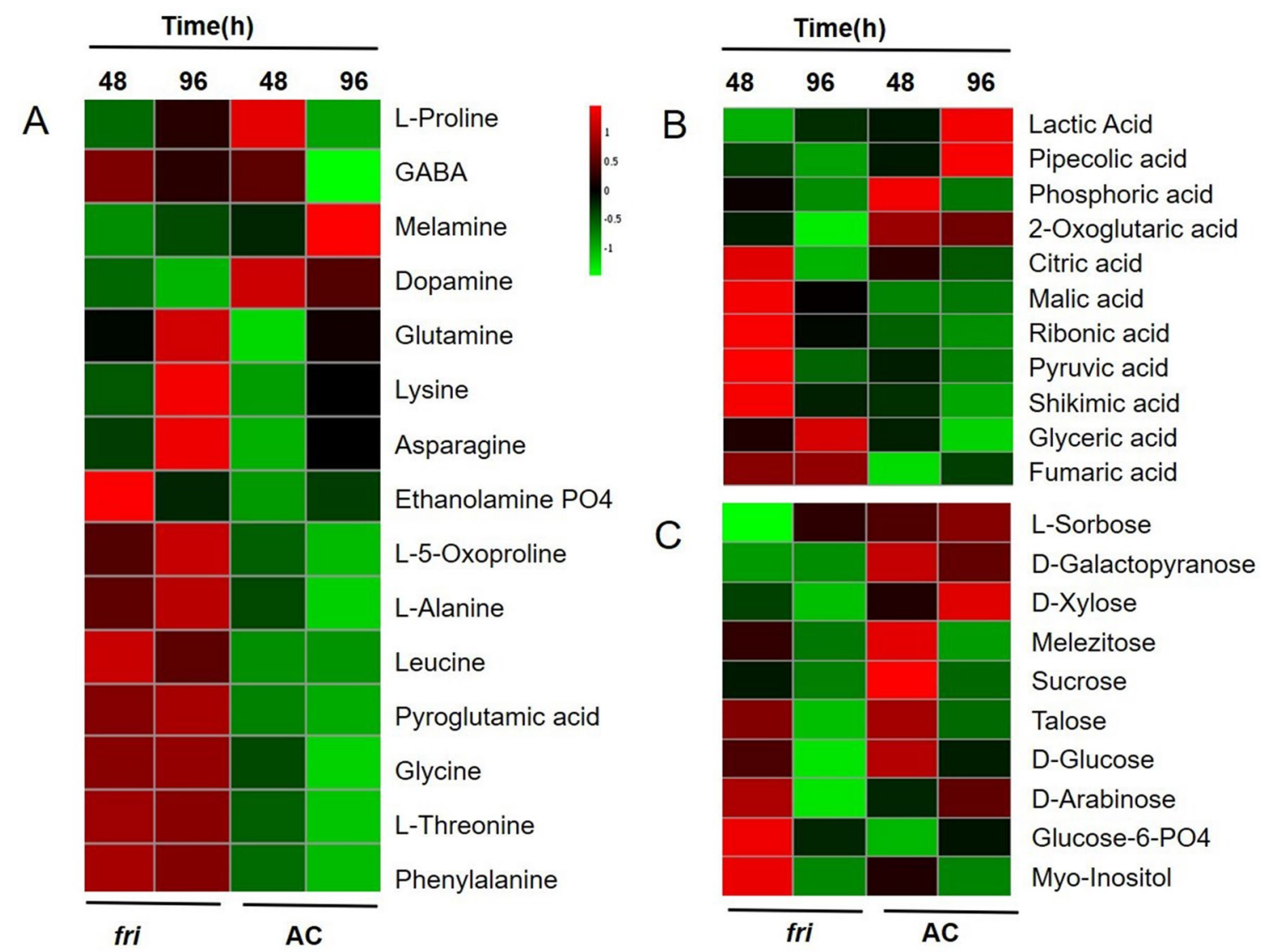

Figure 4. Metabolomic profiling of fri mutant to validate the findings from discovery proteomics. Heat map showing differential expression of $(\mathbf{A})$ amino acids $(\mathbf{B})$ organic acids (C) sugars in the seedlings treated under FR light compared to AC.

plants to adapt to light environments. Proteins associated with chloroplast are the main targets of this regulatory mechanism, which is in line with the observations that phytochrome regulates most chloroplastic functions, including various aspects of photosynthesis ${ }^{101,102}$.

Primary metabolite profiling using GC-MS reveals that PhyA regulates primary metabolism in tomato seedlings. In the study, we used 4 replicates of AC and fri mutant seedlings of tomato, that are grown under FR light and dark in two-time points (48 and $96 \mathrm{~h}$ ) (Fig. 1B) to understand the temporal variation in metabolite accumulation. A total of 77 compounds were identified from 4 replicates. Normalized abundance value of these metabolites at various treatment conditions, is shown in Supplementary Table S2. Statistical analysis was conducted in two groups; AC/FR versus AC/D and fri/FR versus AC/FR. 39 significant compounds were identified for AC/FR versus AC/D, and 49 compounds were identified for fri/FR versus AC/FR. The most prominent group of modulated metabolites belonged to organic sugars, followed by amino acids and organic acids (Fig. 4 and Supplementary Table S2). The mutation in PhyA resulted in a drastic variation in the profile of primary metabolites such as sugars, amino acids, and organic acids (Fig. 4 and Supplementary Fig. S6). Previous reports suggest that Phy signaling has substantial effects on the majority of primary carbon metabolic pathways and a subset of secondary metabolites. Metabolomics experiments comparing Phy mutants with wildtype controls in Arabidopsis and rice ${ }^{7,8,11,50,56,103}$ confirm the same. Even though the results differ, the general trend indicates that a large number of metabolites, particularly sugars and tricarboxylic acid cycle components, accumulate to higher levels in phy mutants compared to wild-type plants.

Jumtee et al. ${ }^{7}$ reported that FR exposure led to a PhyA dependent fall in the levels of sugars (including Glc, Fru, and Gral). As FR light activates de-etiolation but not greening, the carbon resources may be used for growth but not restored through photosynthesis under these conditions. However, studies conducted by a few other groups $^{8,56,104}$ reported reduced sugar levels in phy mutants when compared to the wild type. These studies suggest that the impact of Phy signaling on sugar and starch abundance may be dependent on the developmental stage and/or experimental conditions. Patel et al. ${ }^{103}$ showed that the quality of light has a significant role in the accumulation of soluble sugars, especially sucrose. This is very clear from these findings that although Phy deficiency alters sugar levels, whether it leads to a rise or fall in sugars, will potentially depend on several factors.

We found an accumulation of several organic sugars in the mutant seedlings during $48 \mathrm{~h}$ of FR irradiation. Sugars such as arabinose, myoinositol, glucose 6-phosphate, and talose showed a significantly increased abundance. However, it declined drastically as the irradiation time increased from 48 to $96 \mathrm{~h}$ (Fig. 4C). The decreased 
accumulation is an important clue suggesting that the absence of PhyA-regulated biochemical pathways for several hours could lead to decreased carbon metabolism and the possibility of the sugars being used up for the survival of the mutant. Our metabolite profiling data showed an increased accumulation of several amino acids in fri mutant in the FR (Fig. 4A). We also observed that amino acid levels in the mutant showed no change in their levels over the FR irradiation period ( 48 to $96 \mathrm{~h}$ ).

Additionally, we found a depletion in the amino acid pool in the AC seedling during irradiation (Supplementary Fig. S6). Our results corroborate the previous finding by Liu et al. ${ }^{105}$, where amino acid concentrations drop in wild-type but not in $p h y A$ mutant seedlings during FR-induced de-etiolation. This result indicates that this PhyA-mediated effect may arise from an increase in protein synthesis to support growth, which would deplete the amino acid pool. Increased accumulation of organic acids (Fig. 4B) was observed in the mutant under $48 \mathrm{~h}$ of FR irradiation; however, a drastic decline was observed under $96 \mathrm{~h}$ of treatment. Most of the organic sugars in AC seedlings under FR showed a decrease in their abundance. Previous transcript profiling studies revealed that enzymes catalyzing the synthesis of organic acids were down-regulated in $p h y A B D E$ mutants ${ }^{8}$, suggesting that these metabolites are not elevated through transcriptional up-regulation. Another interpretation is that organic acids accumulate due to decreased synthetic processes that use these metabolites. Regarding the accumulation of organic acids and amino acids, it is currently unclear whether this is because of increased production or slower consumption $^{49}$; however, our proteomics data showed a decreased abundance of several proteins associated with amino acid biosynthesis.

Our temporal proteomics analysis of phyA mutant revealed a wide-ranging influence of PHYA on a myriad of pathways during the onset of photomorphogenesis. PHYA seems to elicit metabolism change by regulating protein levels during heterotrophic to autotrophic transition. Of interest was a set of proteins exhibiting lightindependent accumulation with a significant variation in their levels during the course of $96 \mathrm{~h}$ treatment. It remains to be determined whether the higher abundance of some of these proteins was due to the overall absence of turnover or specifically no turnover under FR.

In conclusion, an integrated protein and metabolite investigation revealed that loss of PHYA significantly impacts on photosynthesis, carbohydrate metabolism, photorespiration, and other metabolic pathways under FR irradiation. The proteomic profiling of tomato phyA mutant delineate its role during FR-mediated photomorphogenesis. The reduced abundance of proteins in the mutant suggests an important role of phyA during FR-mediated growth and development, where it likely interacts with other signaling pathways to regulate the final response (Fig. 5). Overall, our study reveals that phyA through its network of interacting proteins plays a major role in the FR mediated photomorphogenesis.

\section{Methods}

Plant materials and growth condition. The seeds of tomato $c v$. Ailsa Craig (AC) and fri mutant lines carrying a mutation in $P H Y-A^{37}$ were used for this study. The tomato seeds used in this study are publicly available from TGRC, Davis, California. We have complied with all legislation for use of this material. Tomato seeds were surface sterilized in $2 \%(\mathrm{v} / \mathrm{v})$ sodium hypochlorite for 15-20 min, followed by thoroughly washing under running tap water. The surface-sterilized seeds were then transferred on wet germination paper and kept in the dark at $25 \pm 1{ }^{\circ} \mathrm{C}$ for seed germination. The germinated seeds were transferred to germination boxes lined with wet germination paper, were either kept in dark or under continuous $\mathrm{FR}\left(3 \mu \mathrm{mol} / \mathrm{m}^{2} / \mathrm{s}\right)$ at $25 \pm 1{ }^{\circ} \mathrm{C}$ in a culture room. Later, the shoot tissue was harvested after $48 \mathrm{~h}$ and $96 \mathrm{~h}$. After harvest, seedling tissue was immediately snap-frozen using liquid nitrogen and stored at $-80^{\circ} \mathrm{C}$ until use. All of the above experiments were carried out in the darkroom and safe green light was used for the selection of germinated seeds and their transfer on germination paper (sterilized and soaked in autoclaved double distilled water).

Protein extraction and digestion. Total protein was extracted from tomato AC and fri mutant seedlings grown for 48 and $96 \mathrm{~h}$ under FR light and dark using Urea extraction protocol ${ }^{106}$ with slight modification. The seedling samples ( $\sim 100 \mathrm{mg}$ each) were ground to a fine powder using a pestle and mortar in liquid nitrogen, and the frozen powder was then extracted with a urea-based lysis buffer containing $8 \mathrm{M}$ Urea, $50 \mathrm{mM}$ Tris $\mathrm{pH} 8.0$, $75 \mathrm{mM} \mathrm{NaCl}$, and $1 \mathrm{mM} \mathrm{MgCl}_{2}$. Tissue lysis was performed with sonication at $40 \%$ amplitude, $5 \mathrm{~s}$ pulse on, and $5 \mathrm{~s}$ pulse of $2 \mathrm{~min}$ and $30 \mathrm{~s}$ (big probe-Sonics Vibra Cell) by placing the tube on ice throughout the procedure. After the sonication, bead milling (Bertin, MiniLys) at $90 \mathrm{~s}$ for 3 cycles was performed by adding $100 \mathrm{mg}$ of beads $(1.0 \mathrm{~mm}$ dia. ZIRCONIA/SILICA, BioSpec products, Cat No. $11079110 \mathrm{z}$ ) to the tissue lysate in $1.5 \mathrm{ml} / 0.5 \mathrm{ml}$ Eppendorf tubes. Tubes were then centrifuged to get rid of the debris at $8000 \mathrm{rpm}$ (small rotor, Thermo centrifuge) for $15 \mathrm{~min}$ at $4{ }^{\circ} \mathrm{C}$. Clear supernatant $(200-250 \mu \mathrm{l})$ was collected in a fresh tube. Protein estimation was done using a 2D Quant kit (BioRad) as per the manufacturer's protocol. The amount of protein considered for further downstream processing is $100 \mu \mathrm{g}$ unless stated otherwise.

iTRAQ labeling and fractionation. $100 \mu \mathrm{g}$ protein from each sample was digested into peptides with trypsin (Pierce, Madison, USA) for $16 \mathrm{~h}$ at $37^{\circ} \mathrm{C}$, followed by vacuum drying the peptides. Peptides were subsequently cleaned up with C18 desalting columns (Sigma, USA), and then iTRAQ labelling ${ }^{107}$ was performed according to the manufacturer's instructions for the iTRAQ reagents 4-plex kit (AB Sciex Inc., Foster City, California, USA). AC 48 and AC 96 were labeled with iTRAQ tags 114 and 115 respectively, and fri48 and 96 were labeled with iTRAQ tags 116 and 117 (Supplementary Fig. S1). For each sample, three independent biological replicates were performed. After labeling, samples from the same set were combined and lyophilized. The peptide mixtures were dissolved in $0.1 \%$ TFA. The samples were fractionated using a gradient of ACN and triethylamine by eluting the peptide with a linear gradient of 10-90\% ACN in triethylamine. 7 fractions were collected 
Figure 5. Schematic model of PhyA-regulated proteins in tomato seedling grown under FR light. The green ellipse represents proteins downregulated in fri mutant while red showed an upregulation. The brown ellipse represents proteins downregulated in $48 \mathrm{~h}$ but upregulated in $96 \mathrm{~h}$.OEE1-33 kDa precursor protein of oxygen-evolving complex; OEE-The oxygen-evolving enhancer protein; DHLD precursor-dihydrolipoamide dehydrogenase precursor; PDH E1 $\alpha$-Pyruvate dehydrogenase E1 component subunit alpha; $\alpha$ KG- $\alpha$ Ketoglutaric acid; DHLD-dihydrolipoamide dehydrogenase; 2 PG-2-phosphoglycolate; Cyp 1-cysteine protease; Fum-fumaric acid; GAPDH-glyceraldehyde 3-phosphate dehydrogenase; PsbX-psbX photosystem II $23 \mathrm{kDa}$ protein; PsbQ-photosystem II oxygen-evolving complex protein; SBPase-Sedoheptulose 1,7-bisphosphatase; G3P-glyceraldehyde-3 phosphate; PGK-phosphoglycerate kinase; 3-PGA-3-Phosphoglyceric acid; Pyr-pyruvate; RuBP-RuBP: ribulose-1,5bisphosphate; 2-Cys Prx-2-cysteine peroxiredoxin; Mg-prot-IX-Mg-protoporphyrin IX chelatase; GG reductase-Geranylgeranyl reductase; PorB-light-dependent NADH:protochlorophyllide oxidoreductase; Por-light-dependent NADH:protochlorophyllide oxidoreductase 1; MDHARMonodehydroascorbate reductase; Aldolases-(Fructose-bisphosphate aldolase1, Fructose-bisphosphate aldolase2), a sub unit-ATP synthase subunit alpha, GS-chloroplast glutamine synthetase; AMT-Amino methyltransferase; SHMT-Serine hydroxymethyltransferase; GD-glycine decarboxylase; OAA-Oxaloacetate.

and lyophilized prior to the LC-MS/MS analysis. The peptides were quantified using Thermo plate reader and lug of peptide was used for the LC-MS/MS run.

LC-MS/MS analysis. Each fraction was resuspended in $0.1 \%$ formic acid. MS/MS analysis was performed on a hybrid quadrupole Orbitrap (Q Exactive) mass spectrometer (Thermo Fisher Scientific, Bremen, Germany) with high energy collision dissociation (HCD). The MS system was equipped with an automated Easy-nLC 1000 system (Thermo Fisher Scientific, Germerling, Germany). A linear gradient of solvent A ( $0.1 \%$ formic acid) to solvent B (0.1\% formic acid, $99.9 \%$ acetonitrile) was run for $95 \mathrm{~min}$, followed by a ramp to $98 \%$ B for $5 \mathrm{~min}$. The instrument was run in a positive mode applying data-dependent MS scan and MS/MS acquisition ${ }^{108}$. Full scan MS spectra (400-2000 m/z) were acquired with resolution $\mathrm{R}=70,000,170,000$ intensity thresholds, and fixed first mass $=105 \mathrm{~m} / \mathrm{z}$.

Protein identification and data analysis. Proteome Discoverer 1.4 with the SEQUEST algorithm (Thermo Scientific Inc., Bremen, Germany) was used to search the original MS/MS protein data in the specified non-redundant databases. Protein identification was executed against the $\mathrm{SGN}^{109}$ tomato database ITAG3.0. Static modification for the iTRAQ 4-plex run was set to Carbamidomethyl and Oxidation of Methionine as a dynamic modification. Proteome Discoverer nodes for spectrum grouper and spectrum selector were set using default parameters. Tolerances were set to a $10 \mathrm{ppm}$ precursor mass tolerance and a $0.05 \mathrm{Da}$ fragment mass tolerance. 1 maximum missed cleavage sites of trypsin digestion was allowed. Percolator was used for protein identification with parameters set with a strict target false discovery rate (FDR) at 0.01 and a relaxed target FDR at 0.05 . The mass spectrometry proteomics data have been deposited to the ProteomeXchange Consortium via the PRIDE ${ }^{110}$ partner repository with the dataset identifier PXD023589.

Protein networks and functional analysis. Pathway mapping of the differentially regulated proteins $(p<0.05)$ was conducted using the KEGG PATHWAY tool available from the Kyoto Encyclopedia of Genes and Genomes (https://www.genome.jp/kegg/tool/map_pathway2.html29). Metaboanalyst (https://www.metaboanal yst.ca/ $)^{28}$ was used for the generation of heat-map.

Metabolite profiling. For GC-MS based metabolite analysis, we used the same tissue samples from AC and $f r i$, which were previously used for our proteomics study. The metabolites were extracted, analyzed, and identified using the protocol previously described in the ${ }^{111}$. In brief, the polar metabolite fraction was extracted from $100 \mathrm{mg}$ of dry tissue powder by adding mixed with $1.4 \mathrm{ml} 100 \%$ methanol and $60 \mu \mathrm{l}$ of internal standard ribitol $(0.2 \mathrm{mg} / \mathrm{ml}, \mathrm{w} / \mathrm{v})$ and shaken at $70^{\circ} \mathrm{C}$ in a thermomixer for $15 \mathrm{~min}$ at $650 \mathrm{rpm}$. The extract was then mixed with an equal amount of MilliQ water, centrifuged at $2200 \mathrm{~g}$ at $25^{\circ} \mathrm{C}$, and the supernatant was collected. The $150 \mu \mathrm{l}$ of supernatant was dried in the vacuum for $2 \mathrm{~h}$. The sample was dissolved in $80 \mu \mathrm{l}$ of pyridine containing $20 \mathrm{mg} / \mathrm{ml}$ methoxyamine hydrochloride and kept at $37^{\circ} \mathrm{C}$ for $90 \mathrm{~min}$ at $650 \mathrm{rpm}$. Then the samples were derivatized by adding $80 \mu \mathrm{l}$ of $N$-trimethylsilyl- $N$-methyl trifluoroacetamide (MSTFA) and the mixture was incubated at $37^{\circ} \mathrm{C}$ for $30 \mathrm{~min}$ at $650 \mathrm{rpm}$.

The derivatized samples were analyzed using LECO-PEGASUS GCXGC-TOF-MS system (LECO Corporation, USA) equipped with $30 \mathrm{~m}$ Rxi-5 ms column with $0.25 \mathrm{~mm}$ internal diameter and $0.25 \mu \mathrm{m}$ film thickness (Restek, USA). The injection temperature, interface, and ion source were set at 230,250 , and $200{ }^{\circ} \mathrm{C}$ respectively. For separation of groups of metabolites, the following program was used; isothermal heating at $70{ }^{\circ} \mathrm{C}$ for $5 \mathrm{~min}$, followed by $5{ }^{\circ} \mathrm{C} / \mathrm{min}$ oven temperature ramp to $290^{\circ} \mathrm{C}$, and final heating at $290^{\circ} \mathrm{C}$ for $5 \mathrm{~min}$. A $1 \mu \mathrm{l}$ of the sample was injected in splitless mode, and mass spectra were recorded at 2 scans/s within a mass-range from 70 to 600.

Identification of metabolites. The NetCDF files obtained from ChromaTOF software 4.50.8.0 chromatography version (LECO Corporation, USA) were analyzed using MetAlign 3.0 (www.metalign.nl) software ${ }^{112}$ with a signal to noise ratio of $\geq 2$, for baseline correction, noise estimation, alignment, and extraction of ion wise mass signal. The MetAlign results were further processed with MS Clust ${ }^{113}$ software for the reduction of data and compound mass extraction. NIST MS Search v 2.2 software was used for the identification of compounds 


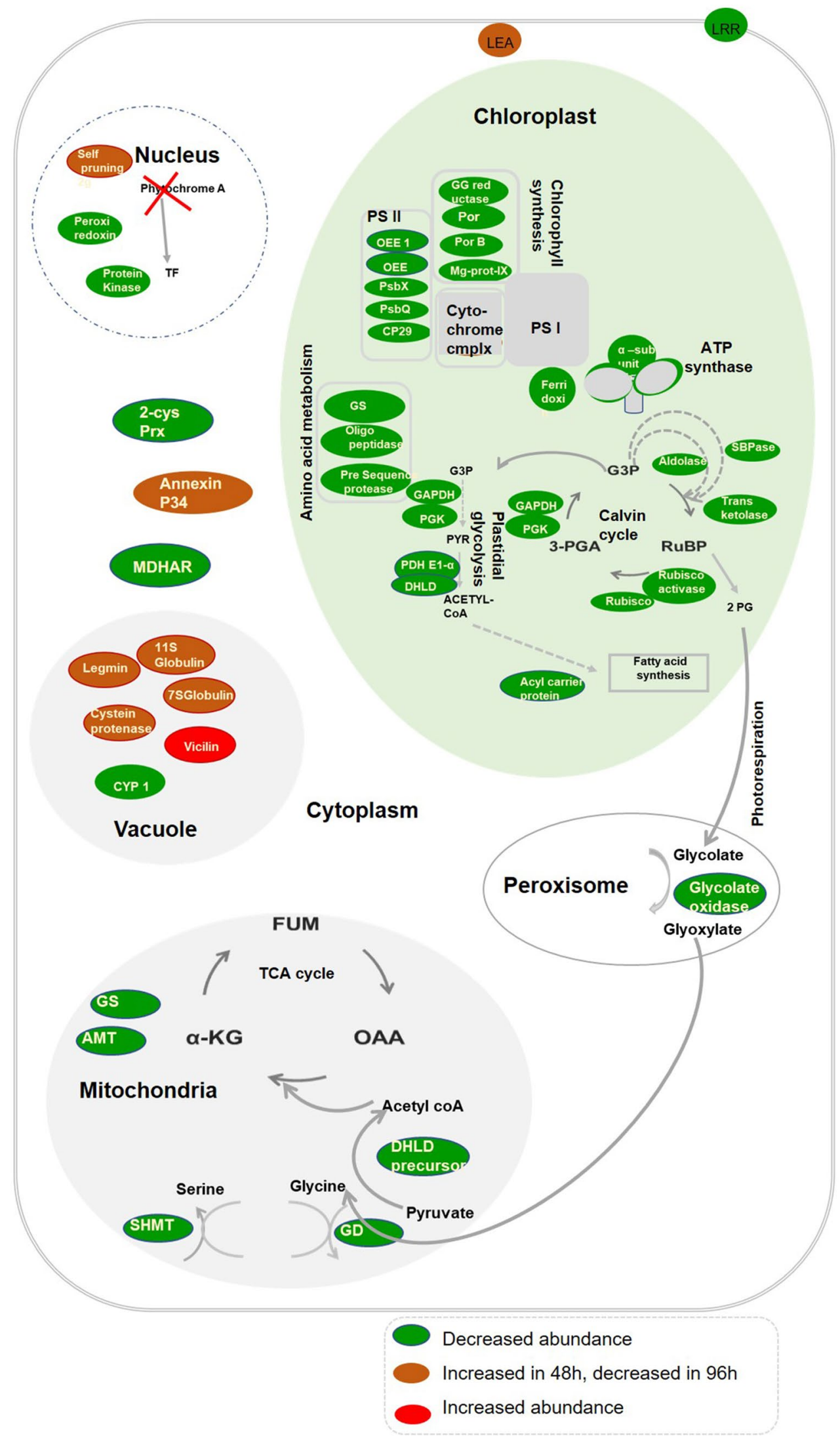


with the NIST (National Institute of Standard and Technology) Library and Golm Metabolome Database Library (http://gmd.mpimp-golm.mpg.de/) ${ }^{114}$. The compound hits with maximum matching factor (MF) value $(>700)$, and the least deviation from the retention index (RI) was used for metabolite identity. The metabolite levels were quantified by normalizing with the concentration of the internal standard (ribitol).

Statistical analysis. In all experiments, 3 biological replicates were used, and the mean with the standard error was calculated. For statistical analysis of metabolite data, including PCA, we used online software MetaboAnalyst 4.0 (http://www.metaboanalyst.ca/) ${ }^{28}$.

Received: 19 May 2020; Accepted: 22 March 2021

Published online: 06 April 2021

\section{References}

1. Møller, S. G., Ingles, P. J. \& Whitelam, G. C. The cell biology of phytochrome signalling. New Phytol. 154, 553-590. https://doi. org/10.1046/j.1469-8137.2002.00419.x (2002).

2. Montgomery, B. L. \& Lagarias, J. C. Phytochrome ancestry: Sensors of bilins and light. Trends Plant Sci. 7, 357-366. https://doi. org/10.1016/S1360-1385(02)02304-X (2002).

3. Galvão, V. C. \& Fankhauser, C. Sensing the light environment in plants: Photoreceptors and early signaling steps. Curr. Opin. Neurobiol. 34, 46-53. https://doi.org/10.1016/j.conb.2015.01.013 (2015).

4. Whitelam, G. C. et al. Phytochrome a null mutants of arabidopsis display a wild-type phenotype in white light. Plant Cell 5, 757-768. https://doi.org/10.1105/tpc.5.7.757 (1993).

5. Darko, E., Heydarizadeh, P., Schoefs, B. \& Sabzalian, M. R. Photosynthesis under artificial light: The shift in primary and secondary metabolism. Philos. Trans. R. Soc. B Biol. Sci. 3, 369. https://doi.org/10.1098/rstb.2013.0243 (2014).

6. Tepperman, J. M., Zhu, T., Chang, H. S., Wang, X. \& Quail, P. H. Multiple transcription-factor genes are early targets of phytochrome A signaling. Proc. Natl. Acad. Sci. USA 98, 9437-9442. https://doi.org/10.1073/pnas.161300998 (2001).

7. Jumtee, K., Bamba, T., Okazawa, A., Fukusaki, E. \& Kobayashi, A. Integrated metabolite and gene expression profiling revealing phytochrome A regulation of polyamine biosynthesis of Arabidopsis thaliana. J. Exp. Bot. 59, 1187-1200. https://doi.org/10. 1093/jxb/ern026 (2008).

8. Yang, D., Seaton, D. D., Krahme, J. \& Halliday, K. J. Photoreceptor effects on plant biomass, resource allocation, and metabolic state. Proc. Natl. Acad. Sci. USA 113, 7667-7672. https://doi.org/10.1073/pnas.1601309113 (2016).

9. Chen, M. \& Chory, J. Phytochrome signaling mechanisms and the control of plant development. Trends Cell Biol. 21, 664-671. https://doi.org/10.1016/j.tcb.2011.07.002 (2011).

10. Demarsy, E. \& Fankhauser, C. Higher plants use LOV to perceive blue light. Curr. Opin. Plant Biol. 12, 69-74. https://doi.org/ 10.1016/j.pbi.2008.09.002 (2009).

11. Jumtee, K. et al. Comprehensive metabolite profiling of phyA phyB phyC triple mutants to reveal their associated metabolic phenotype in rice leaves. J. Biosci. Bioeng. 108, 151-159. https://doi.org/10.1016/j.jbiosc.2009.03.010 (2009).

12. Anderson, N. L. et al. A human proteome detection and quantitation project. Mol. Cell. Proteom. 8, 883-886. https://doi.org/ 10.1074/mcp.R800015-MCP200 (2009).

13. Whiteaker, J. R. The increasing role of mass spectrometry in quantitative clinical proteomics. Clin. Chem. 56, 1373-1374. https:// doi.org/10.1373/clinchem.2010.150383 (2010).

14. Bantscheff, M., Schirle, M., Sweetman, G., Rick, J. \& Kuster, B. Quantitative mass spectrometry in proteomics: A critical review. Anal. Bioanal. Chem. 389, 1017-1031. https://doi.org/10.1007/s00216-007-1486-6 (2007).

15. Sechi, S. \& Oda, Y. Quantitative proteomics using mass spectrometry. Curr. Opin. Chem. Biol. 7, 70-77. https://doi.org/10.1016/ S1367-5931(02)00010-8 (2003).

16. Schulze, W. X. \& Usadel, B. Quantitation in mass-spectrometry-based proteomics. Annu. Rev. Plant Biol. 61, 491-516. https:// doi.org/10.1146/annurev-arplant-042809-112132 (2010).

17. Narumi, R. et al. A strategy for large-scale phosphoproteomics and SRM-based validation of human breast cancer tissue samples. J. Proteome Res. 11, 5311-5322. https://doi.org/10.1021/pr3005474 (2012).

18. Zhang, H. et al. ITRAQ-based quantitative proteomic comparison of early- and late-passage human dermal papilla cell secretome in relation to inducing hair follicle regeneration. PLoS ONE 11(12), e0167474. https://doi.org/10.1371/journal.pone.0167474 (2016).

19. Dowle, A. A., Wilson, J. \& Thomas, J. R. Comparing the diagnostic classification accuracy of iTRAQ, peak-area, spectralcounting, and emPAI methods for relative quantification in expression proteomics. J. Proteome Res. 15, 3550-3562. https://doi. org/10.1021/acs.jproteome.6b00308 (2016).

20. Elliott, M. H., Smith, D. S., Parker, C. E. \& Borchers, C. Current trends in quantitative proteomics. J. Mass Spectrom. 44, 1637-1660. https://doi.org/10.1002/jms.1692 (2009).

21. Simpson, K. L., Whetton, A. D. \& Dive, C. Quantitative mass spectrometry-based techniques for clinical use: Biomarker identification and quantification. J. Chromatogr. B: Anal. Technol. Biomed. Life Sci. 877, 1240-1249. https://doi.org/10.1016/j.jchro mb.2008.11.023 (2009).

22. Wu, W. W., Wang, G., Baek, S. J. \& Shen, R. F. Comparative study of three proteomic quantitative methods, DIGE, cICAT, and iTRAQ, using 2D gel- or LC-MALDI TOF/TOF. J. Proteome Res. 5, 651-658. https://doi.org/10.1021/pr050405o (2006).

23. Hirai, M. Y. et al. Integration of transcriptomics and metabolomics for understanding of global responses to nutritional stresses in Arabidopsis thaliana. Proc. Natl. Acad. Sci. USA 101, 10205-10210. https://doi.org/10.1073/pnas.0403218101 (2004).

24. Weckwerth, W., Wenzel, K. \& Fiehn, O. Process for the integrated extraction, identification and quantification of metabolites, proteins and RNA to reveal their co-regulation in biochemical networks. Proteomics 4, 78-83. https://doi.org/10.1002/pmic. 200200500 (2004).

25. Carrari, F. et al. Integrated analysis of metabolite and transcript levels reveals the metabolic shifts that underlie tomato fruit development and highlight regulatory aspects of metabolic network behavior. Plant Physiol. 142, 1380-1396. https://doi.org/ 10.1104/pp.106.088534 (2006)

26. Kumar, R., Tamboli, V., Sharma, R. \& Sreelakshmi, Y. NAC-NOR mutations in tomato Penjar accessions attenuate multiple metabolic processes and prolong the fruit shelf life. Food Chem. 259, 234-244. https://doi.org/10.1016/j.foodchem.2018.03.135 (2018).

27. Thomas, P. D. et al. PANTHER: A library of protein families and subfamilies indexed by function. Genome Res. 13, 2129-2141. https://doi.org/10.1101/gr.772403 (2003). 
28. Chong, J., Wishart, D. S. \& Xia, J. Using MetaboAnalyst 4.0 for comprehensive and integrative metabolomics data analysis. Curr. Protoc. Bioinform. 68(1), e86. https://doi.org/10.1002/cpbi.86 (2019).

29. Kanehisa, M., Sato, Y., Kawashima, M., Furumichi, M. \& Tanabe, M. KEGG as a reference resource for gene and protein annotation. Nucleic Acids Res 44, D457-D462. https://doi.org/10.1093/nar/gkv1070 (2016).

30. Chou, K. C. \& Shen, H. B. Plant-mPLoc: A top-down strategy to augment the power for predicting plant protein subcellular localization. PLoS ONE 5(6), e11335. https://doi.org/10.1371/journal.pone.0011335 (2010).

31. Whitelam, G. C. \& Devlin, P. F. Roles of different phytochromes in Arabidopsis photomorphogenesis. Plant Cell Environ. 20, 752-758. https://doi.org/10.1046/j.1365-3040.1997.d01-100.x (1997).

32. Deng, X. W. \& Quail, P. H. Signalling in light-controlled development. Semin. Cell Dev. Biol. 10, 121-129. https://doi.org/10. 1006/scdb.1999.0287 (1999).

33. Warpeha, K. M. \& Montgomery, B. L. Light and hormone interactions in the seed-to-seedling transition. Environ. Exp. Bot. 121, 56-65. https://doi.org/10.1016/j.envexpbot.2015.05.004 (2016).

34. McNellis, T. W., von Arnim, A. G. \& Deng, X. W. Overexpression of Arabidopsis COP1 results in partial suppression of lightmediated development: Evidence for a light-inactivable repressor of photomorphogenesis. Plant Cell 6, 1391-1400. https://doi. org/10.1105/tpc.6.10.1391 (1994).

35. Josse, E.-M. \& Halliday, K. J. Skotomorphogenesis: The dark side of light signalling. Curr. Biol. 18, R1144-1146. https://doi.org/ 10.1016/j.cub.2008.10.034 (2008).

36. Barnes, S. A. et al. Phytochrome signal-transduction: Characterization of pathways and isolation of mutants. Philos. Trans. R. Soc. Lond. Ser. B: Biol. Sci. 350, 67-74. https://doi.org/10.1098/rstb.1995.0139 (1995).

37. van Tuinen, A., Kerckhoffs, L. H. J., Nagatani, A., Kendrick, R. E. \& Koornneef, M. Far-red light-insensitive, phytochrome A-deficient mutants of tomato. MGG Mol. Gen. Genet. 246, 133-141. https://doi.org/10.1007/BF00294675 (1995).

38. Barnes, S. A., Nishizawa, N. K., Quaggio, R. B., Whitelam, G. C. \& Chua, N. H. Far-red light blocks greening of Arabidopsis seedlings via a phytochrome A-mediated change in plastid development. Plant Cell 8, 601-615. https://doi.org/10.1105/tpc.8. $4.601(1996)$

39. Runge, S., Sperling, U., Frick, G., Apel, K. \& Armstrong, G. A. Distinct roles for light-dependent NADPH:protochlorophyllide oxidoreductases (POR) A and B during greening in higher plants. Plant J. 9, 513-523. https://doi.org/10.1046/j.1365-313x.1996. 09040513.x (1996).

40. Ballaré, C. L., Scopel, A. L. \& Sánchez, R. A. Far-red radiation reflected from adjacent leaves: An early signal of competition in plant canopies. Science 247, 329-332. https://doi.org/10.1126/science.247.4940.329 (1990).

41. Casal, J. J. \& Smith, H. The function, action and adaptive significance of phytochrome in light-grown plants. Plant Cell Environ. 12, 855-862. https://doi.org/10.1111/j.1365-3040.1989.tb01966.x (1989).

42. Whitelam, G. C. \& Smith, H. Retention of phytochrome-mediated shade avoidance responses in phytochrome-deficient mutants of Arabidopsis, cucumber and tomato. J. Plant Physiol. 139, 119-125. https://doi.org/10.1016/S0176-1617(11)80176-8 (1991).

43. Quail, P. H. Phytochrome genes and their expression. In Photomorphogenesis in Plants (eds Kendrick, R. E. \& Kronenberg, G. H. M.) 71-104 (Springer, Dordrecht, 1994). https://doi.org/10.1007/978-94-011-1884-2_5.

44. Johnson, E., Bradley, M., Harberd, N. P. \& Whitelam, G. C. Photoresponses of light-grown phyA mutants of Arabidopsis: Phytochrome a is required for the perception of daylength extensions. Plant Physiol. 105, 141-149. https://doi.org/10.1104/pp. 105.1.141 (1994).

45. Yanovsky, M. J., Casal, J. J. \& Whitelam, G. C. Phytochrome A, phytochrome B and HY4 are involved in hypocotyl growth responses to natural radiation in Arabidopsis: Weak de-etiolation of the phyA mutant under dense canopies. Plant Cell Environ. 18, 788-794. https://doi.org/10.1111/j.1365-3040.1995.tb00582.x (1995).

46. Robson, P. R., McCormac, A. C., Irvine, A. S. \& Smith, H. Genetic engineering of harvest index in tobacco through overexpression of a phytochrome gene. Nat. Biotechnol. 14, 995-998. https://doi.org/10.1038/nbt0896-995 (1996).

47. Lazarova, G. I. et al. Molecular analysis of PHYA in wild-type and phytochrome A-deficient mutants of tomato. Plant J. 14, 653-662. https://doi.org/10.1046/j.1365-313x.1998.00164.x (1998).

48. Quail, P. H. et al. Phytochromes: Photosensory perception and signal transduction. Science 268, 675-680. https://doi.org/10. 1126/science.7732376 (1995).

49. Krahmer, J., Ganpudi, A., Abbas, A., Romanowski, A. \& Halliday, K. J. Phytochrome, carbon sensing, metabolism, and plant growth plasticity. Plant Physiol. 176, 1039-1048. https://doi.org/10.1104/pp.17.01437 (2018).

50. Ghassemian, M. et al. Integrative analysis of transcript and metabolite profiling data sets to evaluate the regulation of biochemical pathways during photomorphogenesis. Arch. Biochem. Biophys. 448, 45-59. https://doi.org/10.1016/j.abb.2005.11.020 (2006).

51. Hu, W. et al. Unanticipated regulatory roles for Arabidopsis phytochromes revealed by null mutant analysis. Proc. Natl. Acad. Sci. USA 110, 1542-1547. https://doi.org/10.1073/pnas.1221738110 (2013).

52. Nelson, N. \& Yocum, C. F. Structure and function of photosystems I and II. Annu. Rev. Plant Biol. 57, 521-565. https://doi.org/ 10.1146/annurev.arplant.57.032905.105350 (2006).

53. Ding, F., Wang, M., Zhang, S. \& Ai, X. Changes in SBPase activity influence photosynthetic capacity, growth, and tolerance to chilling stress in transgenic tomato plants. Sci. Rep. 6, 32741. https://doi.org/10.1038/srep32741 (2016).

54. Laing, W. A., Stitt, M. \& Heldt, H. W. Control of $\mathrm{CO}_{2}$ fixation. Changes in the activity of ribulosephosphate kinase and fructoseand sedoheptulose-bisphosphatase in chloroplasts. BBA Bioenergetics 637, 348-359. https://doi.org/10.1016/0005-2728(81) 90174-2 (1981).

55. Woodrow, I. E., Murphy, D. J. \& Latzko, E. Regulation of stromal sedoheptulose 1,7-bisphosphatase activity by pH and $\mathrm{Mg}^{2+}$ concentration. J. Biol. Chem. 259, 791-795. https://doi.org/10.1042/bj2530249 (1984).

56. Han, X. et al. Phytochrome A and B regulate primary metabolism in Arabidopsis leaves in response to light. Front. Plant Sci. 8, 1394. https://doi.org/10.3389/fpls.2017.01394 (2017).

57. Carlson, K. D., Bhogale, S., Anderson, D., Tomanek, L. \& Madlung, A. Phytochrome a regulates carbon flux in dark grown tomato seedlings. Front. Plant Sci. 10, 152. https://doi.org/10.3389/fpls.2019.00152 (2019).

58. Fox, A. R., Barberini, M. L., Ploschuk, E. L., Muschietti, J. P. \& Mazzella, M. A. A proteome map of a quadruple photoreceptor mutant sustains its severe photosynthetic deficient phenotype. J. Plant Physiol. 185, 13-23. https://doi.org/10.1016/j.jplph.2015. 07.004 (2015)

59. Eisenberg, D., Gill, H. S., Pfluegl, G. M. U. \& Rotstein, S. H. Structure-function relationships of glutamine synthetasesre. Biochimica et Biophysica Acta Protein Struct. Mol. Enzymol. 1477, 122-145. https://doi.org/10.1016/S0167-4838(99)00270-8 (2000).

60. Taira, M., Valtersson, U., Burkhardt, B. \& Ludwig, R. A. Arabidopsis thaliana GLN2-encoded glutamine synthetase is dual targeted to leaf mitochondria and chloroplasts. Plant Cell 16, 2048-2058. https://doi.org/10.1105/tpc.104.022046 (2004).

61. Chen, M. S. \& Schirch, L. Serine transhydroxymethylase. A kinetic study of the synthesis of serine in the absence of tetrahydrofolate. J. Biol. Chem. 248, 3631-3635. https://doi.org/10.1016/S0021-9258(19)43975-6 (1973).

62. Minina, E. A., Moschou, P. N. \& Bozhkov, P. V. Limited and digestive proteolysis: Crosstalk between evolutionary conserved pathways. New Phytol. 215, 958-964. https://doi.org/10.1111/nph.14627 (2017).

63. van der Hoorn, R. A. L. Plant proteases: From phenotypes to molecular mechanisms. Annu. Rev. Plant Biol. 59, 191-223. https:// doi.org/10.1146/annurev.arplant.59.032607.092835 (2008). 
64. Schonbrunner, E. R. \& Schmid, F. X. Peptidyl-prolyl cis-trans isomerase improves the efficiency of protein disulfide isomerase as a catalyst of protein folding (oxidative folding/cyclophilfin/ribonudease T1). Biochemistry 89, 4510-4513. https://doi.org/10. 1073/pnas.89.10.4510 (1992).

65. Penfield, S., Pinfield-Wells, H. M. \& Graham, I. A. Storage reserve mobilisation and seedling establishment in Arabidopsis. The Arabidopsis Book 4, e0100. https://doi.org/10.1199/tab.0100 (2006).

66. Müntz, K. Proteases and proteolytic cleavage of storage proteins in developing and germinating dicotyledonous seeds. J. Exp. Bot. 47, 605-622. https://doi.org/10.1093/jxb/47.5.605 (1996).

67. Raposo, G. \& Stenmark, H. Membranes and organelles. Curr. Opin. Cell Biol. 20, 357-359. https://doi.org/10.1016/j.ceb.2008. 06.005 (2008)

68. Li, J., Li, G., Wang, H. \& Wang Deng, X. Phytochrome signaling mechanisms. The Arabidopsis Book 9, e0148. https://doi.org/ 10.1199/tab.0148 (2011)

69. Dehesh, K. et al. Arabidopsis HY8 locus encodes phytochrome A. Plant Cell 5, 1081-1088. https://doi.org/10.2307/3869628 (1993).

70. Nagatani, A., Reed, J. W. \& Chory, J. Isolation and initial characterization of Arabidopsis mutants that are deficient in phytochrome A. Plant Physiol. 102, 269-277. https://doi.org/10.1104/pp.102.1.269 (1993).

71. Browse, J., Roughan, P. G. \& Slack, C. R. Light control of fatty acid synthesis and diurnal fluctuations of fatty acid composition in leaves. Biochem. J. 196, 347-354. https://doi.org/10.1042/bj1960347 (1981).

72. Roberts, M. R. \& Paul, N. D. Seduced by the dark side: Integrating molecular and ecological perspectives on the influence of light on plant defence against pests and pathogens. New Phytol. 170, 677-699. https://doi.org/10.1111/j.1469-8137.2006.01707.x (2006).

73. Guo, A., Reimers, P. J. \& Leach, J. E. Effect of light on incompatible interactions between Xanthomonas oryzae pv oryzae and rice. Physiol. Mol. Plant Pathol. 42, 413-425. https://doi.org/10.1006/pmpp.1993.1031 (1993).

74. Genoud, T., Buchala, A. J., Chua, N. H. \& Métraux, J. P. Phytochrome signalling modulates the SA-perceptive pathway in Arabidopsis. Plant J. 31, 87-95. https://doi.org/10.1046/j.1365-313X.2002.01338.x (2002).

75. Chandra-Shekara, A. C. et al. Light-dependent hypersensitive response and resistance signaling against Turnip Crinkle Virus in Arabidopsis. Plant J. 45, 320-334. https://doi.org/10.1111/j.1365-313X.2005.02618.x (2006).

76. Griebel, T. \& Zeier, J. Light regulation and daytime dependency of inducible plant defenses in arabidopsis: Phytochrome signaling controls systemic acquired resistance rather than local defense. Plant Physiol. 147, 790-801. https://doi.org/10.1104/pp.108. 119503 (2008)

77. Devlin, P. F., Yanovsky, M. J. \& Kay, S. A. A genomic analysis of the shade avoidance response in Arabidopsis. Plant Physiol. 133, 1617-1629. https://doi.org/10.1104/pp.103.034397 (2003).

78. Arumingtyas, E. L., Savitri, E. S. \& Purwoningrahayu, R. D. Protein profiles and dehydrin accumulation in some soybean varieties (Glycine max L. Merr) in drought stress conditions. Am. J. Plant Sci. 4, 134-141. https://doi.org/10.4236/ajps.2013.41018 (2013).

79. Kim, H. G. et al. GDSL lipase 1 regulates ethylene signaling and ethylene-associated systemic immunity in Arabidopsis. FEBS Lett. 588, 1652-1658. https://doi.org/10.1016/j.febslet.2014.02.062 (2014).

80. Baier, M. \& Dietz, K. J. Protective function of chloroplast 2-cysteine peroxiredoxin in photosynthesis. Evidence from transgenic Arabidopsis. Plant Physiol. 119, 1407-1414. https://doi.org/10.1104/pp.119.4.1407 (1999).

81. Konopka-Postupolska, D. et al. The role of annexin 1 in drought stress in Arabidopsis. Plant Physiol. 150, 1394-1410. https:// doi.org/10.1104/pp.109.135228 (2009).

82. Sudan, J., Negi, B. \& Arora, S. Oxidative stress induced expression of monodehydroascorbate reductase gene in Eleusine coracana. Physiol. Mol. Biol. Plants 21, 551-558. https://doi.org/10.1007/s12298-015-0327-x (2015).

83. Huang, W., Zhang, S. B. \& Hu, H. Sun leaves up-regulate the photorespiratory pathway to maintain a high rate of $\mathrm{CO}_{2}$ assimilation in tobacco. Front. Plant Sci. 5, 688. https://doi.org/10.3389/fpls.2014.00688 (2014).

84. Zelitch, I., Schultes, N. P., Peterson, R. B., Brown, P. \& Brutnell, T. P. High glycolate oxidase activity is required for survival of maize in normal air. Plant Physiol. 149, 195-204. https://doi.org/10.1104/pp.108.128439 (2009).

85. Maurino, V. G. \& Peterhansel, C. Photorespiration: Current status and approaches for metabolic engineering. Curr. Opin. Plant Biol. 13, 249-256. https://doi.org/10.1016/j.pbi.2010.01.006 (2010).

86. McClung, C. R. et al. Integrated temporal regulation of the photorespiratory pathway. Circadian regulation of two Arabidopsis genes encoding serine hydroxymethyltransferase. Plant Physiol. 123, 381-392. https://doi.org/10.1104/pp.123.1.381 (2000).

87. Khanna, R. et al. Functional profiling reveals that only a small number of phytochrome-regulated early-response genes in Arabidopsis are necessary for optimal deetiolation. Plant Cell 18, 2157-2171. https://doi.org/10.1105/tpc.106.042200 (2006).

88. Takahashi, S., Ogawa, T., Inoue, K. \& Masuda, T. Characterization of cytosolic tetrapyrrole-binding proteins in Arabidopsis thaliana. Photochem. Photobiol. Sci. 7, 1216-1224. https://doi.org/10.1039/b802588f (2008).

89. Antolín-Llovera, M., Ried, M. K. \& Parniske, M. Cleavage of the symbiosis receptor-like kinase ectodomain promotes complex formation with nod factor receptor 5. Curr. Biol. 24, 422-427. https://doi.org/10.1016/j.cub.2013.12.053 (2014).

90. Belkhadir, Y., Yang, L., Hetzel, J., Dangl, J. L. \& Chory, J. The growth-defense pivot: Crisis management in plants mediated by LRR-RK surface receptors. Trends Biochem. Sci. 39, 447-456. https://doi.org/10.1016/j.tibs.2014.06.006 (2014).

91. Jaouannet, M. et al. Plant immunity in plant-aphid interactions. Front. Plant Sci. 5, 663. https://doi.org/10.3389/fpls.2014.00663 (2014).

92. de Carolis, E. \& de Luca, V. 2-Oxoglutarate-dependent dioxygenase and related enzymes: Biochemical characterization. Phytochemistry 36, 1093-1107. https://doi.org/10.1016/S0031-9422(00)89621-1 (1994).

93. Lange, T. Molecular biology of gibberellin synthesis. Planta 204, 409-419. https://doi.org/10.1007/s004250050274 (1998).

94. Toyomasu, T., Kawaide, H., Mitsuhashi, W., Inoue, Y. \& Kamiya, Y. Phytochrome regulates gibberellin biosynthesis during germination of photoblastic lettuce seeds. Plant Physiol. 118, 1517-1523. https://doi.org/10.1104/pp.118.4.1517 (1998).

95. Yamaguchi, S., Smith, M. W., Brown, R. G. S., Kamiya, Y. \& Sun, T. Phytochrome regulation and differential expression of gibberellin 3 $\beta$-hydroxylase genes in germinating Arabidopsis seeds. Plant Cell 10, 2115-2126. https://doi.org/10.1105/tpc.10.12. $2115(1998)$.

96. Tan-Wilson, A. L. \& Wilson, K. A. Mobilization of seed protein reserves. Physiol. Plant 145, 140-153. https://doi.org/10.1111/j. 1399-3054.2011.01535.x (2012).

97. Mazzella, M. A. et al. Phytochrome control of the Arabidopsis transcriptome anticipates seedling exposure to light. Plant Cell 17, 2507-2516. https://doi.org/10.1105/tpc.105.034322 (2005).

98. Leivar, P. \& Monte, E. PIFs: Systems integrators in plant development. Plant Cell 26, 56-78. https://doi.org/10.1105/tpc.113. 120857 (2014).

99. Menon, C., Sheerin, D. J. \& Hiltbrunner, A. SPA proteins: SPAnning the gap between visible light and gene expression. Planta 26, 56-78. https://doi.org/10.1007/s00425-016-2509-3 (2016).

100. Shikata, H. et al. Phytochrome controls alternative splicing to mediate light responses in Arabidopsis. Proc. Natl. Acad. Sci. USA 111, 18781-18786. https://doi.org/10.1073/pnas.1407147112 (2014).

101. Berry, J. O., Yerramsetty, P., Zielinski, A. M. \& Mure, C. M. Photosynthetic gene expression in higher plants. Photosynth. Res. 117, 91-120. https://doi.org/10.1007/s11120-013-9880-8 (2013). 
102. Oh, S. \& Montgomery, B. L. Phytochrome-dependent coordinate control of distinct aspects of nuclear and plastid gene expression during anterograde signaling and photomorphogenesis. Front. Plant Sci. 30, 171. https://doi.org/10.3389/fpls.2014.00171 (2014).

103. Patel, D. et al. Temperature-dependent shade avoidance involves the receptor-like kinase ERECTA. Plant J. 73, 980-992. https:// doi.org/10.1111/tpj.12088 (2013).

104. Fukushima, A. et al. Impact of clock-associated Arabidopsis pseudoresponse regulators in metabolic coordination. Proc. Natl. Acad. Sci. USA 106, 7251-7256. https://doi.org/10.1073/pnas.0900952106 (2009).

105. Wu, S. H., Liu, M. J., Wu, S. H. \& Chen, H. M. Widespread translational control contributes to the regulation of Arabidopsis photomorphogenesis. Mol. Syst. Biol. 8, 566. https://doi.org/10.1038/msb.2011.97 (2012).

106. Zhang, H. et al. Integrated proteogenomic characterization of human high-grade serous Ovarian cancer. Cell 166, 755-765. https://doi.org/10.1016/j.cell.2016.05.069 (2016).

107. Ross, P. L. et al. Multiplexed protein quantitation in Saccharomyces cerevisiae using amine-reactive isobaric tagging reagents. Mol. Cell. Proteom. 3, 1154-1169. https://doi.org/10.1074/mcp.M400129-MCP200 (2004).

108. Kumar, V. et al. Multiplexed quantitative proteomics provides mechanistic cues for malaria severity and complexity. Commun. Biol. 3, 1-19 (2020).

109. Fernandez-Pozo, N. et al. The Sol Genomics Network (SGN)-from genotype to phenotype to breeding. Nucleic Acids Res. 43(6), D1036-D1041. https://doi.org/10.1093/nar/gku1195 (2015).

110. Perez-Riverol, Y. et al. The PRIDE database and related tools and resources in 2019: Improving support for quantification data. Nucleic Acids Res 47(D1), D442-D450 (2019).

111. Roessner, U., Wagner, C., Kopka, J., Trethewey, R. N. \& Willmitzer, L. Simultaneous analysis of metabolites in potato tuber by gas chromatography-mass spectrometry. Plant J. 23, 131-142. https://doi.org/10.1046/j.1365-313X.2000.00774.x (2000).

112. Lommen, A. \& Kools, H. J. MetAlign 3.0: Performance enhancement by efficient use of advances in computer hardware. Metabolomics 8, 719-726. https://doi.org/10.1007/s11306-011-0369-1 (2012).

113. Tikunov, Y. M., Laptenok, S., Hall, R. D., Bovy, A. \& de Vos, R. C. H. MSClust: A tool for unsupervised mass spectra extraction of chromatography-mass spectrometry ion-wise aligned data. Metabolomics 8, 714-718. https://doi.org/10.1007/s11306-0110368-2 (2012).

114. Hummel, J., Strehmel, N., Selbig, J., Walther, D. \& Kopka, J. Decision tree supported substructure prediction of metabolites from GC-MS profiles. Metabolomics 6, 322-333. https://doi.org/10.1007/s11306-010-0198-7 (2010).

\section{Acknowledgments}

Thanks to UGC Woman doctoral fellowship (ST), DST SERB fellowship (RK), DBT (Department of Biotechnology), India grant to RS and YS (BT/PR11671/PBD/16/828/2008) and MASSFIT (Mass Spectrometry Facility, IIT Bombay) (BT/PR13114/INF/22/206/2015) for funding. We thank Mr. Sandip Kumar Patel for the help in performing Q Exative LC/MS-MS experiments.

\section{Author contributions}

S.S, R.S \& S.T conceived and designed the study. S.T performed the proteomics experiments and analyzed the data. R.K performed the metabolomics experiments and data analysis. K.S grew the seedlings and performed light treatment. A.B assisted in processing the proteomic sample. S.T wrote the manuscript. R.K, Y.S, R.S and S.S have critically reviewed and given expert advice for the improvement of the manuscript.

\section{Competing interests}

The authors declare no competing interests.

\section{Additional information}

Supplementary Information The online version contains supplementary material available at https:/doi.org/ 10.1038/s41598-021-87208-9.

Correspondence and requests for materials should be addressed to S.S.

Reprints and permissions information is available at www.nature.com/reprints.

Publisher's note Springer Nature remains neutral with regard to jurisdictional claims in published maps and institutional affiliations.

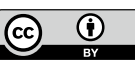

Open Access This article is licensed under a Creative Commons Attribution 4.0 International License, which permits use, sharing, adaptation, distribution and reproduction in any medium or format, as long as you give appropriate credit to the original author(s) and the source, provide a link to the Creative Commons licence, and indicate if changes were made. The images or other third party material in this article are included in the article's Creative Commons licence, unless indicated otherwise in a credit line to the material. If material is not included in the article's Creative Commons licence and your intended use is not permitted by statutory regulation or exceeds the permitted use, you will need to obtain permission directly from the copyright holder. To view a copy of this licence, visit http://creativecommons.org/licenses/by/4.0/.

(C) The Author(s) 2021 